\title{
PORTFÖY SEÇIMİNDE AŞAĞI YÖNLÜ RİSKLERİN KULLANIMI: BIST30 ENDEKSİNDEKİ PAYLAR ÜZERINNE BİR UYGULAMA
}

\author{
UTILIZATION OF DOWNSIDE RISK MEASURES IN PORTFOLIO \\ SELECTION: EVIDENCE FROM BIST30 INDEX
}

Mehmet Emin YILDIZ ${ }^{*}$ iD

Öz

Yatırımcıların kayıplara kazançlardan daha fazla önem vermesi ve getiri serilerindeki asimetrik dağılım, portföy teorisinin ortalama-varyans yaklaşımından ortalama-semivaryans yaklaşımına evrilmesine neden olmuştur. Gelişmekte olan piyasalarda, pay getirilerindeki asimetrik eğilim de aşağı yönlü risk ölçütlerinin kullanımını desteklemektedir. Çalışmanın nihai amacı portföy seçiminde ortalama-varyans yaklaşımının, ortalama-semivaryans yaklaşımından farklı sonuçlara neden olup olmadığını araştırmaktır. Bu doğrultuda BIST30 endeksinde yer alan payların, 2016-2020 yılları arasındaki aylık getirileri kullanılarak Tek Endeksli Piyasa Modeli ile betaları ve aşağı yönlü betaları hesaplanmıştır. Daha sonra CAPM ve D-CAPM uygulanarak elde edilen istenen getiriler, gerçekleşen getiriler ile karşılaştırılmış ve pozitif/negatif alfalı paylar belirlenmiştir. Çalışma sonucunda, betalar ve aşağı yönlü betalar arasındaki fark istatistiksel olarak anlamlı olmasına rağmen hem CAPM hem de D-CAPM kullanılarak portföye alınması veya portföyden çıkarılması gereken payların aynı olduğu ortaya konulmuştur. Diğer bir sonuç da ortalama-semivaryans yaklaşımı kullanılarak yapılan çeşitlendirmenin, ortalama-varyans yaklaşımı kullanarak yapılan çeşitlendirmeden daha başarılı olmadı̆̆ıdır. Çalışmanın sonuçları D-CAPM'in, gelişmekte olan bir piyasa olarak Borsa İstanbul'da, CAPM'den daha yüksek istenen getiriler sunması bakımından da önemlidir.

Anahtar Kelimeler: Aşağı yönlü beta, D-CAPM, semivaryans, modern portföy teorisi, finansal varlık pazar doğrusu

JEL Sınıflandırılması: C21, C23, G11, G12

\section{Abstract}

Portfolio management has evolved from the mean-variance approach to the mean-semivariance approach because the investors have the tendency to prefer avoiding losses to acquiring equivalent gains and the distribution of return series tends to be non-symmetric. The non-symmetric tendency of stock returns

* Dr. Öğr. Üyesi, Doğuş Üniversitesi, İktisadi ve İdari Bilimler Fakültesi, mehmetyildiz@dogus.edu.tr, ORCID: 00000002 71987637

Bu makaleyi alıntılamak için: Ylldız, M. E. (2021). Portföy seçiminde aşağı yönlü risklerin kullanımı: BIST30 endeksindeki paylar üzerine bir uygulama. Journal of Research in Business, 6(2), 332-356.

"Çalışmada Etik Kurul izni gerekmemektedir." 
in Emerging Markets also supports the utilization of downside risk measures. The ultimate purpose of the study is to analyze whether the mean-variance approach in portfolio selection causes different results from the mean-semivariance approach. For this purpose, betas and downside betas were obtained with the Single Index Market Model by using the monthly returns of the stocks within the scope of the BIST30 index between the years 2016-2020. Then, the required returns obtained by applying CAPM and D-CAPM were compared with the realized returns, and the stocks with positive and negative alpha were determined. Although there is a statistically significant difference between betas and downside betas, it is one of the most important results of the study that both CAPM and D-CAPM cause similar results in portfolio selection. Another result is that diversification using the mean-semivariance approach is no more successful than diversification using the mean-variance approach. The results of the study are also important in that D-CAPM generates higher required returns than CAPM in Borsa Istanbul as an Emerging Market.

Keywords: Downside beta, D-CAPM, semivariance, modern portfolio theory, security market line JEL Classification: C21, C23, G11, G12

\section{Extended Summary}

Since Roy (1952), economists have realized that investors care largely about downside losses than they care about upside gains. Markowitz (1959) supports using semivariance as a measure of risk, rather than variance. Because, when returns are normally distributed, both variance and semivariance could be used as risk measures. However, if the return distributions are asymmetric, then only semivariance captures the risk correctly. If the return distribution is positively skewed, then the variance would estimate the risk higher than the actual level. On the contrary, the negatively skewed variance would estimate the risk lower than its actual level (Bodie et al., 2009). More recently, Kahneman and Tversky's (1979) loss aversion preferences, and Gul's (1991) disappointment aversion preferences, allow investors to place greater weights on losses relative to gains in their utility functions. The evolution of the mean-variance approach to the mean-semivariance approach, which is based on downside risks, could be associated with two main reasons: (I) Investors care about largely downward moves than they care upward moves. (II) Semivariance is an appropriate measure of risk when the return distribution is both symmetrical and asymmetrical. Estrada (2002) stated that the semivariance of returns can be used to generate both an alternative behavioral hypothesis (meansemivariance behavior) and an alternative measure of risk for diversified investors (the downside beta) and an alternative pricing model (D-CAPM).

The main purpose of the study is to analyze whether the mean-variance approach in portfolio selection causes different results from the mean-semivariance approach. For this purpose, betas and downside betas were obtained with the Single Index Market Model (Equation 10-11) by using the monthly returns of the stocks within the scope of BIST30 index between the years 2016-2020.

$$
\begin{gathered}
R_{i t}-r_{f t}=\alpha_{i}+\beta_{i}\left(R_{m t}-r_{f t}\right)+e_{i t} \\
R_{i t}-r_{f t}=\beta_{i}^{D}\left(R_{m t}-r_{f t}\right)+e_{i t}
\end{gathered}
$$


Then, the required returns obtained by applying CAPM and D-CAPM (Equation 13-15) were compared with the realized returns in order to determine the stocks with positive and negative alpha.

Although there is a statistically significant difference between betas and downside betas, it is one of the most important results of the study that both CAPM and D-CAPM cause similar results in portfolio selection. Another result is that diversification using the mean-semivariance approach is no more successful than diversification using the mean-variance approach. The results of the study are also important in that D-CAPM generates higher required returns than CAPM in Borsa Istanbul as an Emerging Market.

\section{Giriş}

Markowitz'in (1952) portföy riskini ve getirisini ölçmek için geliştirdiği niceliksel yapı kendisinden önceki yaklaşımlardan farklı olarak getiri kadar riskin de önemli olduğu üzerine kuruluydu. Markowitz (1959) daha sonra yayınladığı kitabı ile etkin çeşitlendirmeyi detaylı olarak inceleyerek Modern Portföy Teorisinin (MPT) temellerini atmış oldu.

Sınırları Markowitz tarafından çizilen çeşitlendirme, aslında yatırımcılar tarafından 1959'da keşfedilmiş değildi. Bu tarihten önce de optimizasyon modeli ortaya koyulmadan çeşitlendirmenin olası yararlarının altı çiziliyordu (Williams, 1938; Hicks, 1935). Fakat, portföyün ne kadar farklı sektöre dağıtılırsa riskin o kadar iyi düşürülüleceği varsayılıyordu veya riskin nereye kadar düşürüleceği tam olarak hesaplan(a)mıyordu. Yine 1952 yılından önce Markowitz’in tez danışmanı Marschak (1938) tarafından getirinin belirsizliği ile ilgili istatistiksel analizler yapılmış ve yatırımcının faydasının sadece beklenen getiriye değil aynı zamanda getirilerdeki değişkenliğe de bağlı olduğu ortaya konulmuştur.

Markowitz, çalışmalarında beklenen getiri, varyans (risk) ve kovaryans ölçütlerini kullanarak etkin sınırı türetmiştir. Etkin sınır üzerindeki portföyler, varyans veri iken beklenen getiriyi maksimize eden, getiri veri iken varyansı minimize eden varlık bileşimlerinden oluşur. Bu portföylerin yatırımcının faydasını maksimize etmeyi amaçladığı söylenebilir. Dolayısıyla Markowitz’e göre yatırıcımcının fayda fonksiyonunu maksimize eden iki paremetre vardır: risk olarak tanımlanan getirilerin varyansı ve beklenen getiri (ortalama getiri). Literatürde buna ortalama-varyans yaklaşımı da denilmektedir. Markowitz’e (1991) göre ortalama-varyans, yatırımcının beklenen faydası ile yüksek korelasyona sahip bir fayda düzeyi vermektedir. Diğer bir deyişle yatırımcılar portföy seçerken sadece ortalama getiri ve varyansı kullansalar bile faydalarını maksimize etmiş sayılırlar.

Ortalama-varyans yaklaşımında bir yatırımcının faydası (U) tamamen portföy getirisinin ortalamasına $\left(\mu_{P}\right)$ ve varyansına $\left(\sigma_{p}^{2}\right)$ bağlıdır.

$$
U=U\left(\mu_{P}, \sigma_{p}^{2}\right)
$$


MPT, ortalama-varyans yaklaşımının beklenen fayda teorisi ile tam olarak tutarlı olduğunu söylemekteydi. Bu tutarlılık, iki önkoşulun varlığında doğrudur. Birinci koşul yatırımcıların fayda fonksiyonunun kuadratik (ikinci dereceden) olmasıdır. İkinci koşul ise yatırımcı portföyünün getirilerinin normal dağılmış olmasıdır. Literatürde iki koşul için de karşıt görüşler yer almaktadır (Pratt, 1964; Feldstein 1969; Arrow, 1971). Grootveld \& Hallerbach’a (1999) göre kuadratik fayda fonksiyonu riskten artan bir şekilde kaçınma anlamına gelmektedir. Oysa bu durum belli bir noktadan sonra negatif marjinal faydaya neden olmaktadır. Gerçek hayatta, özellikle de uzun vadede getiriler normal dağılım özelliği göstermemektedir. Çünkü hisse senetleri ve tahviller için sınırsız kazanç potansiyeli varken, kayıp potansiyeli sınırlıdır (Bir varlık \%100'den fazla düşemez ama yükselebilir). Bu da getirilerin asimetrik davranışını açıklayan koşullardan biridir.

Bunlara rağmen yatırımcılar her zaman risk ve getiri arasında bir denge arayışındadır. Markowitz'in aksine Roy (1952) yatırımciların fayda fonksiyonunu matematiksel bir modele göre belirlemenin olanaksız olduğunu ileri sürmüştür. Nawrocki (1999) de insan olarak adlandırılan biyolojik sistem için fayda fonksiyonunu belirleyen unsurların belirsiz olduğunu ifade etmiştir. Bu durumda, yatırımcıların beklenen faydayı maksimize etmesi üzerine tartışmak da anlamsızdır. Portföy kuramının inşa edilmesinde Markowitz kadar önemli rol oynayan Roy'un amacı, en iyi risk-getiri dengesini belirleyecek pratik bir yöntem geliştirmekti.

Roy’a göre yatırımcılar, ilk önce anaparalarını garanti altına alacak; daha sonra ise bu sermayeyi koruyacak minumum kabul edilebilir bir getiri (minumum acceptable return) arayışına gireceklerdir. Aslında, minumum kabul edilebilir getiri (MAR), yatırım hedeflerine erişilmese bile kazanılması gereken en az getiri olarak tanımlandığında, enflasyon oranı veya risksiz faiz oranından başka bir şey değildir. "Roy’un Önce Güvenlik” tercihi olarak adlandırılan bu yöntem (Roy’s Safety-First), yatırımcıların, felaket düzeyinin (disaster level) veya hedef getirinin altında kalma olasılı̆̆ı en az olan yatırımları tercih edeceklerini ifade eder.

Daha sonra farklı versiyonları Sharpe rasyosu olarak anılacak, Roy (1952) tarafından geliştirilen reward to variablitiy $(\mathrm{R} / \mathrm{V})$ oranı aşağıdaki formülize edilmiştir:

$$
\mathrm{R} / \mathrm{V} \text { oranı }=\frac{(\mathrm{r}-\mathrm{d})}{\mathrm{s}}
$$

Burada, $d$ felaket düzeyini, $r$ ortalama getiriyi ve $s$ ise standart sapmayı temsil etmektedir. Bu oranı en yükseğe çıkarmak demek felaket düzeyinin altında en az kalma olasılığı olan portföylerin seçilmesi demektir. ${ }^{1}$ Bu oran Sharp rasyosundan nerdeyse 14 yıl önce Roy tarafından ortaya konulmasına rağmen, Roy portföy yönetiminde hak ettiği üne kavuşamamıştır. Markowitz (1987), Roy’un amacının R/V oranını kullanarak ortalama varyansa dayalı etkin setleri izlemek olmadığını, eğer öyle olsaydı teorinin adının Roy’un portföy teorisi olabileceğini ifade etmiştir. Çünkü Markowitz 1956 yılına gelene kadar henüz etkin setleri seçmek için genel bir portföy algoritması geliştirmemişti.

1 Daha sonraki çalışmalarda felaket düzeyi yerine hedef getiri ve risksiz faiz oranı da kullanılmışır. Grootveld ve Hallerbach’e (1999) göre felaket düzeyi iflas veya daha az dramatik kötü olasıklarla ilgilidir. 
Roy’un bu çalı̧̧ması, aşağı yönlü risk ölçütlerinin ortaya çıkmasında etkili olmuştur. Aşağı yönlü risk ölçütlerinin kullanıldığı ve portföy teorisinin devamı olan bu yaklaşıma, daha sonra ve ilk defa Brian M. Rom \& Kathleen W. Ferguson (1994) tarafından Post-Modern Portföy Teorisi adı verilecektir. Fakat Nawrocki (1999), semivaryansın akademik çalışmalardaki kullanımının varyans kadar eski olduğunu; bu yüzden aşağı yönlü riskleri veya ortalama-semivaryans yaklaşımını tanımlamak için "post-modern portföy teorisi” başlğ̆ını kullanmanın pazarlama cızırtısından başka bir şey olmadığını ifade eder. Kaplan \& Siegel (1994) de çalışmalarında "Post-modern portföy teorisinin" alternatif bir uygulama olmadığını ileri sürmüşlerdir. Riddles’a göre (2001) yatırımcıların aşağı yönlü risk ölçütlerini kabul etmekte ve kullanmakta geç kalmalarının çeşitli nedenleri vardır. Bilgisayar teknolojisinin yetersizliği ve modelin karmaşıklı̆̆ının yanı sıra yatırımcılar, yeni istatistiki yöntemleri kabul etmekte süpheci olma eğilimindedirler. Aşağı yönlü riskin yatırımcılar tarafından geç kabulündeki diğer bir sebep de standart sapmanın zaten kullanılıyor olmasıdır. Eski bir atasözü; "tek bir saati olan bir adam, saatin kaç olduğunu bilirken; iki saati olan bir adam, hiçbir zaman saatin kaç olduğundan emin değildir” der. Dolayısıyla, yatırımcıların yeni bir istatistiki ölçüye uyum sağlayamamasının nedenlerinden birisi de birbiriyle çelişen sonuçlar çıkarmasıdır.

Markowitz (1959) de kitabında aşağı yönlü risklerin önemini vurgulayarak, yatırımcıların aşağı yönlü riskleri iki sebepten en aza indirmeye çalıştığını söyler: (I) Bir yatırımcı için sadece aşağı yönlü risk ve "önce güvenlik" önemlidir. (II) Menkul kıymet getirileri normal dağılım özelliği göstermeyebilir. $\mathrm{Bu}$ sebepten dolayı aşağı yönlü risk ölçütleri, yatırımcıların normal dağılım özelliği göstermeyen menkul kıymet getirileri ile karşılaştığında doğru karar almasına yardım eder. Markowitz (1959), getiri dağılımı simetrik iken hem varyansın hem de semivaryansın doğru risk ölçütleri olduğunu ortaya koyarken; normal dağılımın olmadığı durumlarda ise sadece aşağı yönlü risk ölçütlerinin riski doğru tanımladığını ifade etmiştir.

Grootveld \& Hallerbach’a (1999) göre asimetrik getiri dağılımı, istenen yukarı yönlü hareketleri istenmeyen aşağı yönlü hareketler kadar sert cezalandırdığı için, varyansı kusurlu bir risk ölçüsü haline getirir. İstenmeyen aşağı yönlü dalgalanmaların arzu edilen yukarı yönlü dalgalanmalardan ayrıştı̆̆ 1 bir risk kavramı, varyansa kıyasla yatırımcıların risk konusundaki sezgileriyle daha uyumludur.

Gerçek hayatta, yatırımcıların boğa piyasasında mümkün olduğunca fazla volatilite aradığı, sadece ayı piyasalarında volatiliteden kaçtığı bilinmektedir. Üstelik yatırımcılar için kaybetmekten kaçınma, kazanç aramaktan daha önceliklidir. Kahneman \& Tversky’nin (1979) kaybetmekten kaçınma (loss aversion) tercihleri ve Gül'ün (1991) hayalkırıklığından kaçınma (dissapointment aversion) tercihleri teorisi, kayıplara, kazançlardan daha fazla ağırlık verilmesine izin vermektedir.

Ortalama-semivaryans yaklaşımı, beklenen fayda teorisi ile uyumlu olduğu gibi davranışsal finans literatüründeki bulgular ile de uyumludur. Geleneksel fayda fonksiyonuna göre yatırımcılar daima riskten kaçınma eğiliminde iken Kahneman \& Tversky’nin (1979) Beklentiler Teorisine göre yatırımcıların riske karşı tutumu kayıp ve kazanç alanına göre değişmektedir. Kahneman \& Tversky’nin (1979) değer fonksiyonu; (i) referans noktasından sapmalara göre tanımlanmaktadır, (ii) 
kazanç alanında konkav (içbükey), kayıp alanında konveks (dışbükey) yapılıdır, (iii) kayıp alanında kazanç alanına göre daha diktir. Diğer bir ifade ile S şeklindeki değer fonksiyonu, kaybetmekten duyulan üzüntünün, eşdeğer bir kazançtan elde edilen hazdan daha fazla olduğunu ifade etmektedir (Bkz.: Şekil 1).

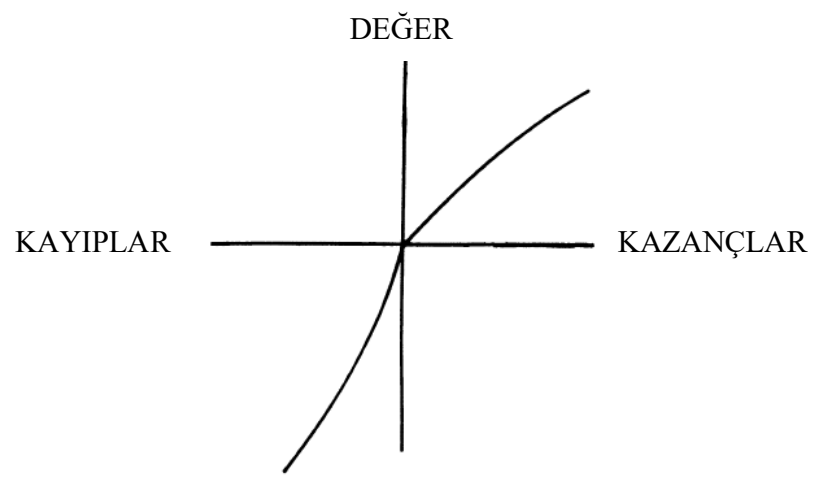

Şekil 1: Değer Fonksiyonu

Beklentiler teorisinde kazanç ve kayıp bir referans değere göre belirlenir ve referans değere göre alınan sonuçlar kazanç alanına giriyorsa riskten kaçınma, kayıp alanına giriyorsa risk arama eğilimi mevcuttur. Oysa geleneksel fayda fonksiyonuna göre yatırımcılar net nakit girişlerini göz önüne alarak her zaman servetlerini maksimize edecek şekilde karar alıyorlardı.

Nihai olarak kayıp durumunun yatırımcı tarafından daha fazla önemsenmesi aşağı yönlü risk kavramı ile tutarlıdır. Kayıp durumunda daha fazla risk arayışı, daha fazla risk primi talep etmeyi gerektirecektir. Piyasa düşerken daha hızlı düşen ama yükselirken aynı hızla yükselmeyen varlıklar iyi bir yatırım seçeneği değildir. Aşağı yönlü risklere daha fazla ağırlık veren yatırımcılar, piyasanın aşağı yönlü hareketlerine yüksek duyarlı hisse senedi tutuyorlarsa bunu telafi etmek için ek prim talep edeceklerdir. Dolayısıyla Ang v.d.ye (2006) göre aşağı yönlü risklerin daha önemli olduğu ekonomilerde piyasanın aşağı yönlü hareketlerine daha duyarlı olan varlıklar yüksek ortalama getirilere sahip olacaktır.

Bu durumda özetle, ortalama-varyans yaklaşımının aşağı yönlü riskler üzerine kurulu olan ortalamasemivaryans yaklaşımına evrilmesi, yatırımcıların kayıplara kazançlardan daha fazla önem vermesi ve getiri serilerideki asimetrik dağılım ile yakından ilişkildir.

Gelişmekte olan ülkelerde getirilerin normal dağılmama eğiliminde olması, varlık getirilerinin aşağı yönlü risk ölçütleri ile daha iyi açıklanabileceğini göstermektedir (Harvey, 2000; Susmel, 2001; Hwang \& Pederson, 2002; Estrada, 2003; Salomans \& Grootveld, 2003; Galagedara 2007; Galagedera \& Brooks, 2007). Çalışmanın amacı, Borsa İstanbul'da portföy seçiminde, ortalama-semivaryans 
yaklaşımından türetilen D-CAPM'in, ortalama-varyans yaklaşımından türetilen CAPM'den farklı sonuçlar ortaya koyup koymadığını araştırmaktır. Başka bir ifade ile bu çalışmada, özellikle gelişmekte olan ülkelerde istatistiksel olarak anlamlı olduğu ileri sürülen aşağı yönlü betaların, portföy seçiminde farklı sonuçlara neden olup olmadığı araştırılmaktadır.

Çalışmanın teorik çerçevesinin, ortalama-varyans yaklaşımından ortalama-semivaryans yaklaşımına geçişi anlattığı için Türkiye'deki literatüre katkı sunması beklenmektedir. Çalışmanın uygulama bölümünün ise hem aşağı yönlü risk ölçütlerinin hesaplanış biçimini göstermesi hem de portföy yönetiminde karar alma sürecine bir yöntem önermesi bakımından uygulayıcılara ve yatırımclara katkı sunacağı düşünülmektedir.

Çalışmanın ikinci bölümünde aşağı yönlü riskler ve ortalama-semivaryans yaklaşımı detaylandırılarak kurulacak modelin teorik çerçevesi çizilecektir.

\section{Ortalama-Semivaryans Yaklaşımı}

MPT, ortalama-varyans yaklaşımının beklenen fayda teorisi ile tam olarak tutarlı olduğunu ileri sürmekteydi. Bunun koşullarından birisi de getirinin normal dağılıma uygun olmasıydı. Pratik uygulamalarda, getiri dağılımının hem normal hem de simetrik olmayışı varyansı tartışmalı bir risk ölçüsü haline getirmektedir. Bu durumda semivaryans, risk için daha uygun bir ölçüt olabilmektedir. Semivaryansın uygun bir risk ölçüsü olmasının üç nedeni vardır. Bunlar:

- Yatırımcının sevmediği yukarı yönlü volatilite değil aşağı yönlü volatilitedir. Farklı bir ifadeyle yatırımclar, kendi minimum kabul edilebilir getirilerinin altında bir getiri elde etmekten korkarlar.

- Semivaryans hem getiri dağılımı simetrik hem de asimetrik iken uygun bir risk ölçüsüdür.

- Semivaryans iki istatistiksel bilgi olan varyans ve çarpıklığı birleştirerek tek bir risk ölçüsü elde eder. Bu da özsermaye maliyeti hesaplanırken tek faktörlü bir model kullanılmasını olanaklı kılar.

Ortalama-semivaryans yaklaşımında yatırımcının toplam faydası aşağıdaki eşitlik ile gösterilmektedir (Estrada, 2002).

$$
U=U\left(\mu_{P}, \Sigma_{p}^{2}\right)
$$

$\Sigma_{p}^{2}$, yatırımcının portföy getirisinin semivaryansını temsil etmektedir. Bu çerçevede tek bir $i$ varlığının riski, getirilerin aşağı yönlü standart sapması ile ölçülmektedir.

$$
\Sigma_{i}=\sqrt{E\left\{\operatorname{Min}\left[\left(R_{i}-\mu_{i}\right) \cdot 0\right]^{2}\right\}}
$$


Aşağı yönlü standart sapma $\left(\sum_{i}\right)$, varlık getirilerinin $\left(R_{i}\right)$ ortalama getiriden $\left(\mu_{i}\right)$ aşağı yönlü sapmaları kullanılarak hesaplanmaktadır. Formül aslında, $i$ varlığının aşağı yönlü standart sapmasının özel bir biçimidir. Buradaki denklem daha genel biçimde aşağıdaki gibi de ifade edilebilmektedir.

$$
\Sigma_{i B}=\sqrt{E\left\{\operatorname{Min}\left[\left(R_{i}-B\right) \cdot 0\right]^{2}\right\}}
$$

Denklem (5)'e göre getiri kriteri (B), ortalama getiri $\left(\mu_{i}\right)$ olabileceği gibi risksiz faiz oranı $\left(R_{f}\right)$ ya da sıfır (0) olabilmektedir. Burada $B$ tam olarak Roy’un (1952) felaket düzeyine karşılık gelmektedir.

Aşağı yönlü risk çerçevesinde, varlığın piyasa ile kovaryansı yerine aşağı yönlü kovaryans veya semikoyaryans $\left(\Sigma_{i M}\right)$ kullanılmaktadır. ${ }^{2}$

$$
\Sigma_{i M}=\mathrm{E}\left\{\operatorname{Min}\left(R_{i}-\mu_{i}, 0\right) \cdot \operatorname{Min}\left(R_{M}-\mu_{M}, 0\right)\right\}
$$

Semikovaryans hem varlığın hem de piyasanın kendi ortalamasının altında kaldığı durumlardaki kovaryansı temsil etmektedir. $R_{M}-\mu_{M}$, piyasa getirisinin kendi ortalamasından sapmasıdır.

Semikovaryans, ilişkinin şiddetini göstermediği için hem varlığın hem de piyasanın aşağı yönlü standart sapmasının çarpımına bölünerek standardize edilir. Bu işlem neticesinde piyasa ve varlık arasındaki aşağı yönlü korelasyon bulunur $\left(\theta_{i M}\right)$.

$$
\theta_{i M}=\frac{\mathrm{E}\left\{\operatorname{Min}\left(R_{i}-\mu_{i}, 0\right) \cdot \operatorname{Min}\left(R_{M}-\mu_{M}, 0\right)\right\}}{\sqrt{E\left\{\operatorname{Min}\left[\left(R_{i}-\mu_{i}\right) \cdot 0\right]^{2}\right\} E\left\{\operatorname{Min}\left[\left(R_{M}-\mu_{M}\right) \cdot 0\right]^{2}\right\}}}
$$

Alternatif olarak semikovaryans, piyasa getirilerinin semivaryansına bölündüğünde $i$ varlığının aşağı yönlü betası bulunur $\left(\beta_{i}^{D}\right)$.

$$
\beta_{i}^{D}=\frac{E\left\{\operatorname{Min}\left(R_{i}-\mu_{i}, 0\right) \cdot \operatorname{Min}\left(R_{M}-\mu_{M}, 0\right)\right\}}{E\left\{\operatorname{Min}\left(R_{M}-\mu_{M}, 0\right)\right\}^{2}}
$$

Hesaplanan aşağı yönlü beta aynı zamanda, varlık ve piyasa portföyü yarı standart sapmaları oranı ile varlık ve piyasa arasındaki aşağı yönlü korelasyon katsayısının çarpımına eşittir.

$$
\beta_{i}^{D}=\frac{\Sigma_{i}}{\Sigma_{M}} x \theta_{i M}
$$

Estrada (2002) getirilerin semi-varyansının, hem alternatif bir davranış hipotezi (ortalamasemivaryans yaklaşımı) hem çeşitlendirilme yapmış yatırımcılar için alternatif bir risk ölçüsü hem de alternatif bir fiyatlama modeli (D-CAPM) üretmek için kullanılabileceğini ifade etmiştir.

2 Literatürde kosemivaryans şeklinde kullanımı da mevcuttur. 


\section{Literatür}

Her ne kadar portföy yönetiminde aşağı yönlü risklerin kullanıldığı kuramsal yapıyı, bazı akademisyenler ve uygulayıcılar Post Modern Portföy Teorisi olarak adlandırsa da semivaryansın kullanımı Markowitz’in 1959 yılındaki çalışmasına kadar uzanmaktadır. Daha önce ise Roy (1952), yatırımcıların, felaket düzeyinin veya hedef getirinin altında kalma olasılığı en az olan yatırımları tercih edeceklerini ifade ederek, literatürde aşağı yönlü risklere referans veren ilk teorisyen olmuştur. Çalışmanın giriş bölümünde aşağı yönlü risklerin ortaya çıkışı kronolojik bir perspektif ile incelenmişti. Bununla birlikte ilgili alanda yapılan çalışmalar daha çok, aşağı yönlü risklerin getirileri açıklayıp açıklayamadığı üzerine yoğunlaşmıştır. Aşağı yönlü risklerin getirileri açıklama gücü, onların, sermaye maliyetinin hesaplanmasında ve dolayısıyla varlık değerlemesinde kullanılması sonucunu doğurmaktadır. Aşağı yönlü risklerin bu kullanım alanı ile ilgili literatür oldukça geniştir; dolayısıyla bu çalışmaların ancak bir kısmına yer verilmiştir. Aşağı yönlü risklerin portföy yönetiminde diğer bir kullanım alanı da optimizasyondur. Bu alanda yapılan çalışmalar, daha çok Markowitz’in (1959) çalışmasında önerdiği semikovaryans hesaplama yönteminin içsel ve asimetrik olması sorununa çözüm önerisi geliştirmek üzerine kuruludur.

Harvey (2000), 28 gelişmekte olan piyasanın ve 19 gelişmiş piyasanın beklenen getirileri üzerinde, açılayıcı etkisi olabilecek 18 risk değişkenini test etmiştir. Çalışmanın önemli bulgularından birisi, semivaryanstan türetilen risk ölçütlerinin getirileri açıklama gücünün sadece gelişmekte olan piyasalarda istatistiksel olarak anlamlı olmasıdır.

Estrada (2000) çalışmasında 28 gelişmekte olan piyasa için 9 adet risk değişkeni hesaplamıştır. Çalışmada; toplam risk, sistematik olmayan risk, ortalamaya göre semivaryans, aşağı yönlü beta ve $\mathrm{VaR}$ değişkenleri ile getiriler arasında anlamlı bir ilişki varken; sistematik risk (beta) ile getiri arasında benzer bir ilişki tespit edilmemiştir. Estrada (2000) gelişmekte olan piyasalarda sistematik riskin anlamsız çıkmasını 4 nedene bağlamıştır: (i) Gelişmekte olan piyasalar dünya piyasaları ile tam olarak entegre olmamıştır. (ii) Dünya piyasası endeksi ortalama-varyans etkisine sahip değildir. Dolayısıyla piyasa portföyünün standart sapmasından elde edilen betalar ile hisse getirileri arasında ilişki yoktur. (iii) Açıklayıcı değişkenler eksik olabilir. Piyasa Değeri/Defter değeri ve momentum gibi ek değişkenler modelin açıklama gücünü değiştirebilir. (iv) Uzun dönemde getiriler ve betalar ilişkisizdir çünkü bunların gerçek değerleri zaman içinde değişmektedir. Estrada’nın (2000) çalışmasının sonuçları gelişmekte olan piyasalarda CAPM'in neden başarısız olduğunu da göstermesi bakımından önemlidir. Estrada (2001), sektör getirileri ile risk değişkenleri arasındaki ilişkiyi de incelemiştir. Ülkeler düzeyinde yapılan çalışmadan farklı olarak bu çalışmada, toplam risk anlamsız, sistematik risk ve ortalamaya göre semivaryans anlamlı çıkmıştır. Estrada (2002), diğer bir çalışmasında ortalama-semivaryans yaklaşımını kullanarak alternatif bir fiyatlama modeli olan D-CAPM'i ortaya koymuştur. Bu çalışmada ortalama-semivaryans yaklaşımından türetilen aşağı yönlü risk değişkenlerinin açıklayıcılık gücünün, ortalama-varyans yaklaşımından türetilen risk değişkenlerinin açıklayıcılık gücünden daha fazla olduğunu ortaya koymuştur. Estrada (2003), bir diğer çalışmasında ise daha çarpık getiri dağılımına sahip gelişmekte olan piyasalarda, aşağı yönlü risk ölçütlerinin daha iyi performans gösterdiğini ortaya koymuştur. Estrada \& Serra (2005), 
gelişmekte olan piyasalarda istenen getiri oranını tahmin etmek için kullanılan değişken sayısının gelişmiş ülkelere kıyasla daha fazla olduğunu ifade etmiştir. Çalışmanın istatistiki sonuçlarına göre, getiri ile ilişkili olan tek risk değişkeni piyasa değeri/defter değeri (PD/DD) değişkenidir. Estrada \& Serra, çalışmanın istatistiki olarak başarısız olmasının nedenini, risk değişkenlerinin reddinden ziyade yatay kesit regresyonu üzerine kurulan global fiyatlama varsayımının reddi olarak açıklamıştır.

Ang, Chen \& Xing (2006), NYSE, AMEX ve NASDAQ borsalarını kapsayan çalışmalarında yüksek volatil olanları hariç - hisse senetlerinin büyük çoğunluğunun tarihi aşağı yönlü betalarının gelecekteki getirileri öngörebildiğini tespit etmiştir. Galagedara (2007) çalışmasında, CAPM betası ve literatürde yer alan üç farklı aşağı yönlü beta arasındaki ilişkileri incelemiştir. Toplam 27 gelişmekte olan piyasanın 1994 ve 2004 yılları arasındaki verilerinin kullanıldığı modelde, CAPM betası ve aşağı yönlü betalar arasındaki ilişki; piyasa portföyünün çarpıklığına, basıklığına ve standart sapmasına bağlıdır. Çalışmanın sonuçlarına göre farklı piyasalarda farklı risk değişkenlerinin anlamlı olması, her piyasanın kendi doğası (yapısı) ile ilgilidir. Alles \& Murray’n (2008) Asya piyasaları üzerine yaptığı çalışmada, aşağı yönlü betaların yukarı yönlü betalara kıyasla; beta, varyans, çarpıklık ve "co-skewness" ile birlikte kullanıldığında göreceli olarak anlamlı kaldığını ortaya koymuştur. Beach (2011), semivaryans ve aşağı yönlü betaların ülkelerin yatay kesit getirilerini açıklamada güçlü bir rol oynadığını ortaya koymuştur. Mikova \& Teplova (2011) çalışmasında, Rus piyasaları için aşağı yönlü risk ölçütlerinin yatay kesit getirileri açıllama gücünün, geleneksel risk ölçütlerine göre daha fazla olduğunu ortaya koymuştur. Atilgan \& Demirtaş (2013), beklenen getiriler ve aşağı yönlü riskler arasındaki ilişkinin gelişmiş ülkelerde daha zayıf olduğunu ortaya koyulmuştur. Tsai, Chen \& Yang'ın (2014) 23 gelişmiş ülke endeksini kullandığı çalışmasının sonuçları, aşağı yönlü betanın sezgisel olarak varyanstan daha cazip olduğunu göstermektedir. Boakye \& O’Malley (2016) aşağ yönlü beta ve semivaryansın, Güney Afrika piyasasındaki getirileri açıklama gücünün istatistiksel olarak anlamlı olduğunu; fakat beta ve standart sapmadan daha uygun birer risk ölçütü olduğunu destekleyen herhangi bir kanıta ulaşılmadığını ifade etmişlerdir. Yildiz \& Erzurumlu’nun (2017), BIST-100 kapsamındaki hisse senetleri üzerine yaptığı çalışmanın sonuçları da ortalama-semivaryans yaklaşımına dayalı risk ölçütlerinin açıklayıcılık güçlerinin daha yüksek olduğunu ortaya koymuştur. Ali (2019), Çin piyasalarında aşağı yönlü betaların başarılı alım-satım stratejileri ürettiğini ileri sürerken beta için aynı bulguya ulaşılamamıştır. Yildiz, Erzurumlu \& Kurtuluş (2020) aşağı yönlü betaların getirileri açıklamada CAPM betasına göre daha başarılı olduğunu ortaya koymuşlardır.

Aşağı yönlü betaların literatürdeki bu başarısı, onları hem sermaye maliyetinin hesaplanmasında hem de optimizasyonda kullanmayı kaçınılmaz hale getirmektedir. Bu çalışma ise aşağı yönlü risklerin getirileri açıklama gücünü araştırmak yerine, onların portföy yönetiminde ortalamavaryans yaklaşımından farklı sonuçlar ortaya koyup koymadığını araştırmayı amaçlamaktadır. 


\section{Veri ve Metodoloji}

Çalışmada BIST30 endeksi kapsamında yer alan payların ve BIST100 endeksinin, 2016-2020 yılları arasındaki aylık getirileri kullanılmıştır. ${ }^{3}$ Her bir risk değişkeninin ve getirinin 60 gözlem temel alınarak hesaplanması literatürde genel kabul gören bir uygulamadır (Brealey v.d., 2008: 242-243). Bu getiriler kullanılarak payların 60 aylık ortalama getirileri, standart sapmaları ve Denklem (4) yolu ile de aşağı yönlü standart sapmaları hesaplanmıştır. Tablo (1), BIST30 endeksinde yer alan payların 2016-2020 yılları arasındaki aylık getirilerinin tanımlayıcı istatistiklerini göstermektedir.

Tablo 1: Tanımlayıcı İstatistikler

\begin{tabular}{ll}
\hline Tanımlayıcı İstatistikler & \\
\hline Ortalama & 0.0240 \\
Standart Hata & 0.0029 \\
Ortanca & 0.0158 \\
Standart Sapma & 0.1234 \\
Varyans & 0.0152 \\
Basıklık & 8.8706 \\
Çarpıklık & 1.4465 \\
Aralık & 1.6640 \\
En Büyük & -0.3667 \\
En Küçük & 1.2973 \\
Toplam & 43.2208 \\
Gözlem & 1800 \\
\hline
\end{tabular}

Hisse senedi getirileri ve piyasa endeksi getirisi (BIST100) hesaplandıktan sonra betalar, Sharpe (1964) tarafından geliştirilen tek faktörlü piyasa modeli temel alınarak hesaplanmıştır.

$$
R_{i t}-r_{f t}=\alpha_{i}+\beta_{i}\left(R_{m t}-r_{f t}\right)+e_{i t}
$$

$R_{i t}, i$ payının $t$ dönemindeki getirisi, $r_{f t}$ aylık mevduat faizi, $R_{m t} \mathrm{t}$ dönemindeki BIST100 endeksinin getirisini temsil etmektedir. Son olarak $e_{i t},{ }$ hisse senedinin $t$ dönemindeki hata terimidir. ${ }^{4}$

Aşağı yönlü betalar $\left(\beta_{i}^{D}\right)$, Denklem (8) yardımı ile hesaplanabilir ama pratikte aşağı yönlü betaları hesaplamak için tek faktörlü piyasa modelinin sabitsiz versiyonu daha kullanışlı ve basittir. Onun için $\alpha_{i}$ modelden çıkarılmıştır (Estrada, 2002). Sabitsiz kullanılan tek faktörlü modelin ekonometrik temeli, Searle (1971) tarafından geliştirilen sabitsiz regresyon denklemine dayanmaktadır.

$$
R_{i t}-r_{f t}=\beta_{i}^{D}\left(R_{m t}-r_{f t}\right)+e_{i t}
$$

3 Veriler Matriks Bilgi Dağıtım Hizmetleri A.Ş.den alınmıştır.

4 Mevduat faizleri TCMB web sayfasından alınmıștır. 
Denklem(11)'deki $R_{i t}$ ve $R_{m t}$ ortalamaya göre koşullu getirilerdir (conditional returns). Bu durumda regresyon denklemi sadece, her bir payın aylık getirilerinin kendi ortalamasının altında kaldığı durumlar ile BIST100 endeksinin aylık getirilerinin kendi ortalamasının altında kaldığ durumlarda çalıştırılacaktır. Aşağı yönlü betaları ve betaları elde etmek için kullanılan iki modelde de getiriler, risksiz faiz oranının üzerindeki ek getirilerdir (excess return).

Aşağı yönlü korelasyonlar $\left(\theta_{i M}\right)$ Denklem (7) kullanılarak hesaplanmıştır. ${ }^{5}$ Tüm hesaplamalar Microsof Excel yazılımı kullanılarak yapılmışır. ${ }^{6}$ Tüm hesaplamaların sonuçları Tablo (2) ve Tablo (3)'de gösterilmiştir.

Bir varlığın portföye dahil edilme kararı, onun için katlanılan riski telafi edebilecek bir istenen getiri sunup sunmamasına bağlıdır. $\mathrm{Bu}$ amaçla CAPM ve D-CAPM kullanılarak istenen getiriler hesaplanmış ve bu getiriler payların gerçekleşen getirileri ile karşılaştırılmıştır. Her iki yaklaşıma göre tespit edilen pozitif ve negatif alfalı paylar, aktif strateji izleyen yatırımcıların pay ve dolayısıyla portföy seçiminde kullanılabilmektedir. Benzer yöntemler Kim \& Singal (1997) ile Beach (2006) tarafından gelişmekte olan piyasalar için uygulanmıştır.

$$
E\left(R_{i}\right)=R_{f}+\beta_{i}\left(E\left(R_{M}\right)-R_{f}\right)
$$

Piyasalar dengede iken yatırımcının beklediği getiri oran $1^{7}$ CAPM denklemi ile belirlenir. CAPM'in önermesi her ne kadar "ex-ante" veya beklenen getiriler üzerine olsa da gerçek hayatta "ex-post" veya gerçekleşen getiriler kullanılmaktadır (Bodie v.d., 2009: 292). Dolayısıyla Denklem (12) aşağıdaki şekilde yeniden düzenlenebilir.

$$
k_{i}=R_{f}+\beta_{i}\left(R_{M}-R_{f}\right)
$$

Burada $k_{i}$ piyasa dengede iken CAPM'in önerdiği istenen getiri oranıdır. $R_{f}$ aylık mevduat faizlerinin 2016-2020 arasındaki 60 aylık ortalamasıdır. BIST-30 paylarının betaları denklem (10) kullanılarak elde edilmişti. Gelişmekte olan piyasa olarak sınıflandırılan Borsa İstanbul için tarihsel bir piyasa risk primi $\left(R_{M}-R_{f}\right)$ hesaplamanın bazı sıkıntıları vardır. ${ }^{8}$ Gelişmekte olan piyasalar için; yetersiz çeşitlendirme, negatif risk primi ile sonuçlanan yüksek volatiliteli dönemler, veri setinin yeterli uzunluğa sahip olmaması, risk primini kullanısssı kılacak yüksek standart hatalar, risksiz faiz oranının ne olacağı, piyasa risk primi hesaplanmasındaki zorluklardan bazılarıdır. ${ }^{9}$ Bu sebeplerden

5 Aşağı yönlü betaları $\left(\beta_{i}^{D}\right)$ hesaplandıktan sonra, aşağı yönlü korelasyonları hesaplamanın daha pratik bir yolu da $\beta_{i}^{D}=\theta_{i, m} \times \frac{\Sigma_{i}}{\Sigma_{m}}$ denklemini kullanmaktır. Burada daha önceden hesaplanan pay ve endeksin aşağ yönlü standart sapmalarına $\left(\Sigma_{i}, \Sigma_{m}\right)$ da ihtiyaç duyulmaktadır.

6 Regresyon sonuçları ve korelasyon matrisleri Excel Veri Çözümleme modülü kullanılarak elde edilmiştir.

7 Bu terim Literatürde "requried return", "fair expected return" veya "market capitalization rate" olarak geçmektedir (Bodie v.d., 2009)

8 Borsa İstanbul için 2001-2020 arasındaki yıllar dikkate alınarak hesaplanan piyasa risk primi \% 2,91 ile gelişmiş ülkelerden daha düşük bir risk primi sunmaktadır. Hesaplamaya 2000 yılı da dahil edildiğinde gerek Borsa İstanbul’un negatif getirisi gerekse de risksiz faiz oranındaki uç değerler negatif bir piyasa risk primi hesaplanmasına neden olmaktadır.

9 Bu alandaki literatür oldukça geniştir. Çalışmalardan bazıları (Marisca \& Lee, 1993; Erb, Harvey \& Viskanta, 1995; 
dolayı Türkiye için Damodaran tarafından önerilen piyasa risk primi kullanılmıştır. Türkiye için yıllık \%8,10; aylık ise \%0,65 olan piyasa risk primi, $\mathrm{ABD}$ piyasaları için kullanılan piyasa risk priminin $(\% 4,72)$ CDS primlerine göre düzeltilmiş versiyonudur. ${ }^{10}$

Denklem (14) yolu ile elde tutma dönemindeki aylık getiriler (realized/actual) hesaplanmıştır. Fiyatlar temettü ödemesini dikkate alacak şekilde düzeltilmiştir.

$$
r_{i}=\frac{P_{T}}{P_{T-1}}
$$

CAPM tarafından önerilen istenen getiriler (ki) ile gerçekleşen getirilerin (ri) 60 aylık ortalaması karşılaştırıldığında 3 farklı durum ortaya çıkmaktadır:

\section{Durum $1: R_{i}>k_{i}$ \\ Durum $2: R_{i}<k_{i}$ \\ Durum $3: R_{i}=k_{i}$}

Durum l'e göre ilgili pay FVPD’nin (SML) üzerinde yer alır (pozitif alfalı pay). Bu durumda aktif strateji takip eden yatırımcılar, ilgili payın portföydeki ağırlığını artırırlar veya ilgili payı portföylerine dahil ederler. Durum 2'ye göre ilgili pay FVPD’nin altında yer alır (negatif alfalı pay). Bu durumda aktif strateji takip eden yatırımcılar, ilgili payın portföydeki ağırlı̆̆ını azaltırlar veya ilgili payı portföylerinden çıkarırlar. Durum 3’e göre ilgili payın gerçek değeri ile piyasa değerinin eşit olduğu; diğer bir ifade ile FVPD içinde yer aldığı ifade edilebilir. Bu durumda ilgili payın portföydeki ağırlığı değiştirilmez ve tutulmaya devam edilir.

Benzer analizler aşağı yönlü betalar kullanılarak da uygulanmıştır. D-CAPM yoluyla istenen getirileri bulmak için aşağıdaki denklem kullanılır:

$$
k_{i}^{d}=R_{f}+\beta_{i}^{D}\left(R_{M}-R_{f}\right)
$$

Burada $k_{i}^{d}$ piyasa dengede iken D-CAPM'in önerdiği istenen getiri oranıdır. Kullanılan risksiz faiz oranı ve piyasa riski primi Denklem (13) ile ortaktır. Aşağı yönlü betalar ise $\left(\beta_{i}^{D}\right)$ Denklem (11) yolu

Godfrey \& Espinosa, 1996; Lessard 1996; Pereiro 2001; Harvey 2001; Estrada, 2002; Bodnar, Dumas \& Marston 2003; Fuenzalida \& Mongrut, 2010; Donadelli \& Prosperi, 2011; Damodaran, 2013)

10 Bu oranlar Damodaran’ın web sitesinde aylık olarak güncellenmektedir. http://pages.stern.nyu.edu/ adamodar/ (Erișim Tarihi 01.02.2021). BIST100 endeksinin getirisi ve risksiz faiz oranı kullanılarak da piyasa risk primi hesaplanmıştır. 20 yıllık aritmetik ortalama kullanılarak hesaplanan piyasa risk primi sadece \%2,91 çıkmıştır. Bu oran, ABD için hesaplanan \%4,72'lik piyasa risk priminin altında olduğu için kullanışsızdır. Diğer bir ifade ile \%2,91'lik piyasa risk priminin ülke riskini içermediği düşünülebilir. 
ile hesaplanmaktadır. D-CAPM kullanılarak hesaplanan istenen getiriler, gerçekleşen getirileri ile karşılaştırılarak pozitif ve negatif alfalı paylar tekrar bulunmuştur. Burada en temel amaç ortalamavaryans yaklaşımına dayalı betalar ile ortalama-semivaryans yaklaşımına dayalı aşağı yönlü betalar kullanılarak elde edilen pozitif ve negatif alfalı payların seçiminde bir farklılık olup olmadığını ortaya koymaktır. İki farklı yaklaşıma göre hesaplanan risk ölçütleri de karşılaştırılarak analiz tamamlanmaya çalışlacaktır.

\section{Bulgular}

Tablo (2) ortalama-varyans yaklaşımı kullanılarak elde edilen risk değişkenlerini ve diğer değişkenleri gösterirken Tablo (3) ortalama-semivaryans yaklaşımı kullanılarak elde edilen risk değişkenlerini ve diğer değişkenleri içermektedir.

Tablo 2: Ortalama-Varyans Yaklaşımına göre Risk Değişkenleri ve Diğer Değişkenler

\begin{tabular}{|c|c|c|c|c|c|c|c|c|c|}
\hline Pay & $\mathbf{R}_{\mathrm{i}}$ & $\mathbf{s}_{\mathrm{i}}$ & $\mathbf{s}_{\mathrm{i}} / \mathbf{s}_{\mathrm{m}}$ & $\mathbf{r}_{\mathrm{iM}}$ & $\begin{array}{l}\text { Sharp } \\
\text { Rasyosu }\end{array}$ & $\boldsymbol{\beta}_{\mathrm{i}}$ & $\mathbf{k}_{\mathrm{i}}$ & Alfa & $\begin{array}{l}\text { Çeşitlendirmede } \\
\text { olsun mu? }\end{array}$ \\
\hline AKBNK & $0.96 \%$ & $10.0 \%$ & 1.45 & 0.86 & -0.003 & 1.25 & $1.80 \%$ & $-0.84 \%$ & HAYIR \\
\hline ARCLK & $1.98 \%$ & $10.3 \%$ & 1.49 & 0.51 & 0.097 & 0.76 & $1.48 \%$ & $0.50 \%$ & EVET \\
\hline ASELS & $2.97 \%$ & $9.6 \%$ & 1.39 & 0.53 & 0.206 & 0.74 & $1.46 \%$ & $1.50 \%$ & EVET \\
\hline BIMAS & $2.19 \%$ & $6.1 \%$ & 0.88 & 0.57 & 0.200 & 0.50 & $1.31 \%$ & $0.88 \%$ & EVET \\
\hline DOHOL & $4.00 \%$ & $15.0 \%$ & 2.17 & 0.30 & 0.201 & 0.65 & $1.40 \%$ & $2.60 \%$ & EVET \\
\hline EKGYO & $0.48 \%$ & $10.7 \%$ & 1.55 & 0.64 & -0.047 & 0.99 & $1.62 \%$ & $-1.14 \%$ & HAYIR \\
\hline EREGL & $3.92 \%$ & $10.6 \%$ & 1.54 & 0.63 & 0.277 & 0.96 & $1.61 \%$ & $2.31 \%$ & EVET \\
\hline GARAN & $1.36 \%$ & $10.9 \%$ & 1.58 & 0.83 & 0.035 & 1.32 & $1.84 \%$ & $-0.48 \%$ & HAYIR \\
\hline GUBRF & $6.04 \%$ & $18.3 \%$ & 2.65 & 0.48 & 0.277 & 1.28 & $1.82 \%$ & $4.23 \%$ & EVET \\
\hline HALKB & $-0.37 \%$ & $10.7 \%$ & 1.55 & 0.79 & -0.126 & 1.23 & $1.78 \%$ & $-2.15 \%$ & HAYIR \\
\hline ISCTR & $1.41 \%$ & $10.1 \%$ & 1.46 & 0.82 & 0.042 & 1.19 & $1.76 \%$ & $-0.35 \%$ & HAYIR \\
\hline KCHOL & $1.68 \%$ & $9.0 \%$ & 1.31 & 0.86 & 0.077 & 1.12 & $1.71 \%$ & $-0.03 \%$ & HAYIR \\
\hline KOZAA & $6.06 \%$ & $19.9 \%$ & 2.88 & 0.36 & 0.255 & 1.04 & $1.66 \%$ & $4.40 \%$ & EVET \\
\hline KOZAL & $4.43 \%$ & $14.4 \%$ & 2.08 & 0.46 & 0.240 & 0.95 & $1.60 \%$ & $2.83 \%$ & EVET \\
\hline KRDMD & $4.05 \%$ & $15.1 \%$ & 2.18 & 0.74 & 0.203 & 1.61 & $2.03 \%$ & $2.02 \%$ & EVET \\
\hline MGROS & $2.09 \%$ & $10.8 \%$ & 1.56 & 0.65 & 0.103 & 1.01 & $1.64 \%$ & $0.45 \%$ & EVET \\
\hline OYAKC & $2.74 \%$ & $11.3 \%$ & 1.63 & 0.35 & 0.156 & 0.58 & $1.36 \%$ & $1.38 \%$ & EVET \\
\hline PETKM & $2.62 \%$ & $10.5 \%$ & 1.51 & 0.67 & 0.157 & 1.02 & $1.64 \%$ & $0.98 \%$ & EVET \\
\hline PGSUS & $4.00 \%$ & $18.2 \%$ & 2.64 & 0.64 & 0.165 & 1.70 & $2.09 \%$ & $1.91 \%$ & EVET \\
\hline SAHOL & $1.17 \%$ & $8.7 \%$ & 1.27 & 0.89 & 0.021 & 1.13 & $1.71 \%$ & $-0.55 \%$ & HAYIR \\
\hline SISE & $2.43 \%$ & $9.9 \%$ & 1.43 & 0.65 & 0.147 & 0.93 & $1.59 \%$ & $0.84 \%$ & EVET \\
\hline TAVHL & $1.39 \%$ & $11.2 \%$ & 1.62 & 0.58 & 0.037 & 0.94 & $1.59 \%$ & $-0.20 \%$ & HAYIR \\
\hline TCELL & $1.51 \%$ & $7.7 \%$ & 1.11 & 0.75 & 0.069 & 0.83 & $1.52 \%$ & $-0.01 \%$ & HAYIR \\
\hline THYAO & $1.73 \%$ & $12.7 \%$ & 1.84 & 0.68 & 0.059 & 1.26 & $1.80 \%$ & $-0.07 \%$ & HAYIR \\
\hline TKFEN & $3.43 \%$ & $11.7 \%$ & 1.70 & 0.57 & 0.209 & 0.96 & $1.61 \%$ & $1.82 \%$ & EVET \\
\hline TSKB & $2.41 \%$ & $19.1 \%$ & 2.77 & 0.22 & 0.075 & 0.62 & $1.38 \%$ & $1.03 \%$ & EVET \\
\hline
\end{tabular}




\begin{tabular}{llllllllll} 
TTKOM & $1.32 \%$ & $9.7 \%$ & 1.40 & 0.74 & 0.034 & 1.04 & $1.66 \%$ & $-0.35 \%$ & HAYIR \\
TUPRS & $1.83 \%$ & $9.4 \%$ & 1.37 & 0.64 & 0.090 & 0.87 & $1.55 \%$ & $0.29 \%$ & EVET \\
VAKBN & $1.00 \%$ & $11.1 \%$ & 1.60 & 0.80 & 0.002 & 1.28 & $1.82 \%$ & $-0.81 \%$ & HAYIR \\
YKBNK & $1.22 \%$ & $10.9 \%$ & 1.58 & 0.79 & 0.022 & 1.25 & $1.80 \%$ & $-0.58 \%$ & HAYIR \\
\hline Ortalama & $\mathbf{2 . 4 0 \%}$ & $\mathbf{1 1 . 8} \%$ & $\mathbf{1 . 7 1}$ & $\mathbf{0 . 6 3}$ & $\mathbf{0 . 1 0 9}$ & $\mathbf{1 . 0 3}$ & $\mathbf{1 . 6 5} \%$ & $\mathbf{0 . 7 5} \%$ & \\
BIST-100 & $\mathbf{1 . 4 5 \%}$ & $\mathbf{6 . 9 \%}$ & & & $\mathbf{0 . 0 6 8}$ & $\mathbf{1 . 0 0}$ & & & \\
\hline
\end{tabular}

$R_{i}:$ Ortalama getiri, $\sigma_{i}:$ Paylarm standart sapma, $\sigma_{i} / \sigma_{m}:$ Pay standart sapmasinm BIST100 endeksinin standart sapmasina orani, $\rho_{i m}:$ Paylar ve BIST100 endeksi arasindaki korelasyon, $\beta_{i}$ : Paylarm BIST100 endeksine göre hesaplanan betast, $k_{i}$ : CAPM'in paylar için önerdiği istenen getiri, tüm değişkenler 60 aylik veri kullamilarak hesaplanmıştır.

Tablo 3: Ortalama-Semivaryans Yaklaşımına göre Risk Değişkenleri ve Diğer Değişkenler

\begin{tabular}{|c|c|c|c|c|c|c|c|c|c|c|c|}
\hline Pay & $\mathbf{R}_{\mathrm{i}}$ & $\mathbf{S}_{\mathrm{i}}$ & Çarpıklık & $\mathrm{S}_{\mathrm{i}}^{2} / \mathrm{s}_{\mathrm{i}}^{2}$ & $\mathrm{~S}_{\mathrm{i}} / \mathrm{S}_{\mathrm{m}}$ & $\mathbf{q}_{\mathrm{iM}}$ & $\begin{array}{l}\text { Sharp } \\
\text { Rasyosu } \\
\end{array}$ & $\boldsymbol{\beta}_{\mathrm{i}}^{\mathrm{D}}$ & $\mathbf{k}_{\mathrm{i}}^{\mathrm{D}}$ & Alfa & $\begin{array}{l}\text { Çeşitlendirmede } \\
\text { olsun mu? }\end{array}$ \\
\hline AKBNK & $0.96 \%$ & $7.0 \%$ & 0.15 & $48.1 \%$ & 1.40 & 0.89 & -0.004 & 1.24 & $1.79 \%$ & $-0.83 \%$ & HAYIR \\
\hline ARCLK & $1.98 \%$ & $7.3 \%$ & -0.09 & $50.3 \%$ & 1.47 & 0.65 & 0.136 & 0.95 & $1.60 \%$ & $0.38 \%$ & EVET \\
\hline ASELS & $2.97 \%$ & $6.7 \%$ & 0.11 & $48.7 \%$ & 1.35 & 0.80 & 0.296 & 1.08 & $1.68 \%$ & $1.28 \%$ & EVET \\
\hline BIMAS & $2.19 \%$ & $4.0 \%$ & 0.44 & $44.3 \%$ & 0.81 & 0.68 & 0.300 & 0.55 & $1.34 \%$ & $0.85 \%$ & EVET \\
\hline DOHOL & $4.00 \%$ & $8.5 \%$ & 1.77 & $32.2 \%$ & 1.71 & 0.65 & 0.355 & 1.11 & $1.70 \%$ & $2.30 \%$ & EVET \\
\hline EKGYO & $0.48 \%$ & $6.8 \%$ & 0.83 & $40.1 \%$ & 1.36 & 0.73 & -0.074 & 0.99 & $1.63 \%$ & $-1.15 \%$ & HAYIR \\
\hline EREGL & $3.92 \%$ & $7.3 \%$ & 0.29 & $46.8 \%$ & 1.46 & 0.72 & 0.405 & 1.06 & $1.67 \%$ & $2.25 \%$ & EVET \\
\hline GARAN & $1.36 \%$ & $7.4 \%$ & 0.40 & $45.8 \%$ & 1.49 & 0.87 & 0.051 & 1.29 & $1.82 \%$ & $-0.46 \%$ & HAYIR \\
\hline GUBRF & $6.04 \%$ & $9.7 \%$ & 1.64 & $28.1 \%$ & 1.95 & 0.70 & 0.522 & 1.37 & $1.87 \%$ & $4.17 \%$ & EVET \\
\hline HALKB & $-0.37 \%$ & $7.3 \%$ & 0.18 & $46.8 \%$ & 1.47 & 0.86 & -0.184 & 1.26 & $1.80 \%$ & $-2.17 \%$ & HAYIR \\
\hline ISCTR & $1.41 \%$ & $7.1 \%$ & 0.04 & $50.5 \%$ & 1.44 & 0.84 & 0.060 & 1.21 & $1.77 \%$ & $-0.36 \%$ & HAYIR \\
\hline KCHOL & $1.68 \%$ & $6.3 \%$ & 0.11 & $48.0 \%$ & 1.26 & 0.89 & 0.112 & 1.12 & $1.71 \%$ & $-0.03 \%$ & HAYIR \\
\hline KOZAA & $6.06 \%$ & $11.7 \%$ & 1.02 & $34.5 \%$ & 2.36 & 0.68 & 0.434 & 1.60 & $2.02 \%$ & $4.04 \%$ & EVET \\
\hline KOZAL & $4.43 \%$ & $8.9 \%$ & 0.98 & $38.6 \%$ & 1.80 & 0.71 & 0.387 & 1.28 & $1.81 \%$ & $2.62 \%$ & EVET \\
\hline KRDMD & $4.05 \%$ & $9.3 \%$ & 1.04 & $38.2 \%$ & 1.88 & 0.79 & 0.329 & 1.48 & $1.94 \%$ & $2.11 \%$ & EVET \\
\hline MGROS & $2.09 \%$ & $7.6 \%$ & -0.04 & $50.0 \%$ & 1.54 & 0.68 & 0.145 & 1.05 & $1.67 \%$ & $0.42 \%$ & EVET \\
\hline OYAKC & $2.74 \%$ & $6.1 \%$ & 2.02 & $29.2 \%$ & 1.23 & 0.68 & 0.288 & 0.84 & $1.53 \%$ & $1.21 \%$ & EVET \\
\hline PETKM & $2.62 \%$ & $7.6 \%$ & -0.34 & $52.6 \%$ & 1.53 & 0.72 & 0.216 & 1.10 & $1.70 \%$ & $0.92 \%$ & EVET \\
\hline PGSUS & $4.00 \%$ & $11.8 \%$ & 0.59 & $41.5 \%$ & 2.37 & 0.79 & 0.257 & 1.88 & $2.20 \%$ & $1.79 \%$ & EVET \\
\hline SAHOL & $1.17 \%$ & $5.9 \%$ & 0.29 & $46.3 \%$ & 1.20 & 0.89 & 0.031 & 1.06 & $1.67 \%$ & $-0.51 \%$ & HAYIR \\
\hline SISE & $2.43 \%$ & $7.2 \%$ & -0.12 & $52.9 \%$ & 1.45 & 0.81 & 0.202 & 1.17 & $1.74 \%$ & $0.69 \%$ & EVET \\
\hline TAVHL & $1.39 \%$ & $7.8 \%$ & 0.25 & $48.6 \%$ & 1.57 & 0.71 & 0.053 & 1.12 & $1.71 \%$ & $-0.32 \%$ & HAYIR \\
\hline
\end{tabular}




\begin{tabular}{llllllllllll} 
TCELL & $1.51 \%$ & $5.5 \%$ & -0.20 & $52.4 \%$ & 1.12 & 0.76 & 0.095 & 0.85 & $1.53 \%$ & $-0.02 \%$ & HAYIR \\
THYAO & $1.73 \%$ & $8.7 \%$ & 0.15 & $46.7 \%$ & 1.75 & 0.85 & 0.086 & 1.48 & $1.95 \%$ & $-0.22 \%$ & HAYIR \\
TKFEN & $3.43 \%$ & $8.3 \%$ & -0.02 & $50.0 \%$ & 1.67 & 0.73 & 0.295 & 1.22 & $1.77 \%$ & $1.65 \%$ & EVET \\
TSKB & $2.41 \%$ & $8.2 \%$ & 4.94 & $18.6 \%$ & 1.66 & 0.78 & 0.174 & 1.30 & $1.82 \%$ & $0.59 \%$ & EVET \\
TTKOM & $1.32 \%$ & $6.6 \%$ & 0.20 & $46.5 \%$ & 1.33 & 0.75 & 0.051 & 0.99 & $1.63 \%$ & $-0.31 \%$ & HAYIR \\
TUPRS & $1.83 \%$ & $6.6 \%$ & 0.02 & $48.8 \%$ & 1.33 & 0.69 & 0.129 & 0.91 & $1.58 \%$ & $0.26 \%$ & EVET \\
VAKBN & $1.00 \%$ & $7.7 \%$ & 0.13 & $48.1 \%$ & 1.54 & 0.86 & 0.003 & 1.33 & $1.84 \%$ & $-0.84 \%$ & HAYIR \\
YKBNK & $1.22 \%$ & $7.8 \%$ & 0.09 & $50.7 \%$ & 1.57 & 0.82 & 0.031 & 1.29 & $1.82 \%$ & $-0.60 \%$ & HAYIR \\
\hline Ortalama & $\mathbf{2 . 4 0} \%$ & $\mathbf{7 . 6} \%$ & $\mathbf{0 . 5 6}$ & $\mathbf{4 4 . 1} \%$ & $\mathbf{1 . 5 3}$ & $\mathbf{0 . 7 7}$ & $\mathbf{0 . 1 7 3}$ & $\mathbf{1 . 1 7}$ & $\mathbf{1 . 7 4 \%}$ & $\mathbf{0 . 6 6 \%}$ & \\
BIST-100 & $\mathbf{1 . 4 5} \%$ & $\mathbf{5 . 0} \%$ & $\mathbf{- 0 . 1 0}$ & $\mathbf{5 1 . 7 \%}$ & & & $\mathbf{0 . 0 9 4}$ & $\mathbf{1 . 0 0}$ & & & \\
\hline
\end{tabular}

$R_{i}:$ Ortalama getiri, $\Sigma_{i}:$ Aşağı yönlü standart sapma, $\Sigma_{i}^{2} / \sigma_{i}^{2}:$ Aşağ yönlü varyansin varyansa oranı, $\Sigma_{i} / \Sigma_{m}:$ Payların aşağ yönlü standart sapmasının BIST100 endeksinin aşağ l yönlü standart sapmasına oranı, $\theta_{i M}$ : Paylar ve BIST100 endeksi arasındaki aşağ l yönlü korelasyon, $\beta_{i}^{D}$ : Payların BIST100 endeksine göre hesaplanan aşağ̀ yönlü betası, $k_{i}^{D}:$ D-CAPM'in paylar için önerdiği istenen getiri, tüm değişkenler 60 aylık veri kullanilarak hesaplanmıştır.

Aşağı yönlü betası, betasından büyük 24 adet pay varken betanın daha büyük değere sahip olduğu pay sayısı 6'dır. Aşağı yönlü betaların betalardan daha büyük olduğu durumlardaki oransal fark ortalama \%22,6; betaların aşağ1 yönlü betalardan daha büyük olduğu durumlardaki oransal fark ise sadece \%3,6'dır. Bu bulguları destekleyecwek bir biçimde betaların ortalaması 1,03 iken aşağı yönlü betaların ortalaması 1,17'dir. Bu bulgular, gelişmekte olan piyasalar sınıfındaki Türkiye'de, D-CAPM'in CAPM'den daha yüksek bir istenen getiri ve bununla paralel olarak daha düşük bir gerçek değer sunabileceğini göstermektedir. Bu sonuç, aşağı yönlü betaların - özellikle gelişmekte olan ülkelerde - daha yüksek istenen getirilere neden olduğunu ortaya koyan literatür ile tutarlıdır (Estrada, 2003; Beach, 2006; Ang v.d., 2006; Estrada, 2007; Foong \& Goh, 2010; Y1ldız v.d. 2020).

Her bir payın standart sapmasının BIST100 endeksinin standart sapmasına oranı $\left(\frac{\sigma_{i}}{\sigma_{m}}\right)$, ortalama 1,71 iken her bir payın aşağı yönlü standart sapmasının BIST 100 endeksinin aşağ1 yönlü standart sapmasına oranı $\left(\frac{\Sigma_{i}}{\Sigma_{m}}\right)$ ortalama 1,53'tür. Bu bulguyu destekleyecek bir biçimde 27 pay için $\frac{\sigma_{i}}{\sigma_{m}}$ oranı, $\frac{\Sigma_{i}}{\Sigma_{m}}$ oranından büyüktür. Her iki bulgu da ortalama-semivaryans yaklaşımına göre yapılan çeşitlendirmenin, riski (aşağı yönlü standart sapmayı) düşürmedeki başarısının, ortalama-varyans yaklaşımından daha iyi olmadığını göstermektedir. ${ }^{11}$

Payların BIST100 endeksi ile korelasyonları $\left(\rho_{i M}\right)$, ortalama 0,63 iken aşağı yönlü korelasyonları $\left(\theta_{i M}\right)$ ortalama 0,77'dir. Üstelik, her bir payın BIST100 endeksine göre hesaplanan aşağı yönlü korelasyon katsayısı, korelasyon katsayısından daha büyüktür. Bu bulgu, ortalama-semivaryans yaklaşımına göre yapılan çeşitlendirmenin neden daha az başarılı olduğunu açıklamak için kullanılabilir. Diğer bir ifadeyle paylar, piyasa aşağı yönlü hareket ederken daha büyük korelasyonlara sahiptir ve bu durum çeşitlendirmenin etkinliğini azaltmaktadır. Global piyasaların aşağı yönlü hareketlerde birbirleriyle

11 Burada BIST100 endeksinin çeşitlendirilmiş bir portföy olduğu varsayılmıştır. 
daha fazla korele olması bulaşma etkisi ile açıklanmaktaydı. Burada, benzer ilişki yerel piyasadaki varlıklar arasında da görülmektedir.

EK (1) paylar arasındaki korelasyonları, EK (2) ise paylar arasındaki aşağı yönlü korelasyonları göstermektedir. Pay çiftleri arasındaki tüm aşağı yönlü korelasyonların ortalaması 0,63 tür. Pay çiftleri arasında 0,34'ten daha düşük aşağı yönlü korelasyon katsayısına ulaşmak mümkün değilken tüm korelasyonların ortalaması sadece 0,39'dur. Bu bulgular da ortalama-semivaryans yaklaşımı ile yapılan çeşitlendirmenin neden daha az başarılı olduğunun ilave bir kanıtı olabilir. Burada dikkat edilmesi gereken noktalardan birisi de herhangi bir pay çifti arasında negatif aşağı yönlü korelasyon elde etmenin matematiksel olarak mümkün olmadığıdır.

Literatüre göre ortalama-semivaryans yaklaşımı ile türetilen risk ölçütleri özellikle asimetrik dağılıma sahip gelişmekte olan ülkelerde istatistiksel olarak anlamlı sonuçlar vermekteydi. 2016 ve 2021 yılları arasında BIST100 endeksinin aylık getiri dağılımı negatif çarpık iken 24 pay pozitif çarpıklığa sahiptir (Bknz.: Tablo 3). Sağa çarpık getiri dağılımı standart sapmayla hesaplanan toplam riski olduğundan yüksek gösterecektir çünkü beklentiden (ortalamadan) aşırı pozitif sapmalar (bunlar yatırımcının endişe kaynağı değildir) tahmin edilen volatiliteyi arttıracaktır. Diğer taraftan negatif çarpıklık durumunda ise standart sapma riski olması gerekenden daha düşük hesaplayacaktır (Bodie v.d.,2009: 133). Negatif çarpıklığa sahip 6 adet payın tamamında aşağı yönlü riskin toplam riske oranı en az \%50’dir. Aşağı yönlü riskin toplam risk içindeki payının \%50 ve daha büyük olduğu 8 pay vardır ve bunların ortalaması sadece $\% 51,2$ 'dir.

Çalışmada, 19 adet payın Sharp rasyosu BIST100 endeksinin Sharp rasyosundan yüksektir. BIST100 endeksinin standart sapmasından küçük tek bir pay varken (BIMAS) katlanılan riske karşllık elde edilen getirinin, BIST100 endeksinden yüksek olduğu 19 pay vardır. Diğer bir ifade ile bu bulgu, BIST 100 endeksinin en iyi risk getiri bileşimine sahip çeşitlendirilmiş portföy olmadığını göstermektedir. Oysa CAPM'in temel varsayımlarından birisi, piyasa portföyünün ortalama-varyans yaklaşımına göre etkin olduğuydu. ${ }^{12}$ Literatürde piyasa endeksinin ortalama varyans etkinliğine sahip olmayabildiğini ileri süren çalışmalar da vardır (Kandel 1984, Mackinlay \& Richardson, 1991; Faff \& Lau, 1997; Estrada, 2000;). Ortalama-semivaryans yaklaşımından türetilen Sharp rasyolarına göre de benzer sonuçlar vardır. Diğer bir ifade ile aşağı yönlü standart sapma kullanılarak hesaplanan Sharp rasyosuna göre de 19 pay, BIST100 endeksinden daha iyi bir risk-getiri bileşimine sahiptir.

CAPM'in önerdiği getiriler ile payların gerçekleşen getirileri karşılaştırıldığında 17 adet pay pozitif alfalıdır. Diğger bir ifade ile 17 adet pay FVPD’nin üzerinde yer almaktadır ve aktif strateji takip eden yatırımcılar tarafından portföye dahil edilmelidir (veya ağırlıkları arttırılmalıdır). Pozitif alfalı paylar aylık ortalama \%1,76 ilave prim sunmaktadır. Şekil (2) FVPD’yi ve payları göstermektedir. ${ }^{13}$

12 Sermaye pazar doğrusunun etkin portföy setini teğet geçtiği nokta olan piyasa portföyü BIST100 endeksi değildir de denilebilir. Ya da BIST100 endeksi tam farklılaştırılmış portföy değildir. Optimum portföylerden oluşan etkin set grafiği çizilmiştir ve istenildiği takdirde paylaşılacaktır.

13 Şekil (2) ve Şekil (3)'de X ekseni 0,50'den başlatılarak payların görünürlüğü arttırılmıştır. Yakınlaştırılmamış diyagramda finansal varlık pazar doğrusunun Y eksenini kestiği nokta, risksiz faiz oranına karşılık gelen \%0,98’dir. 


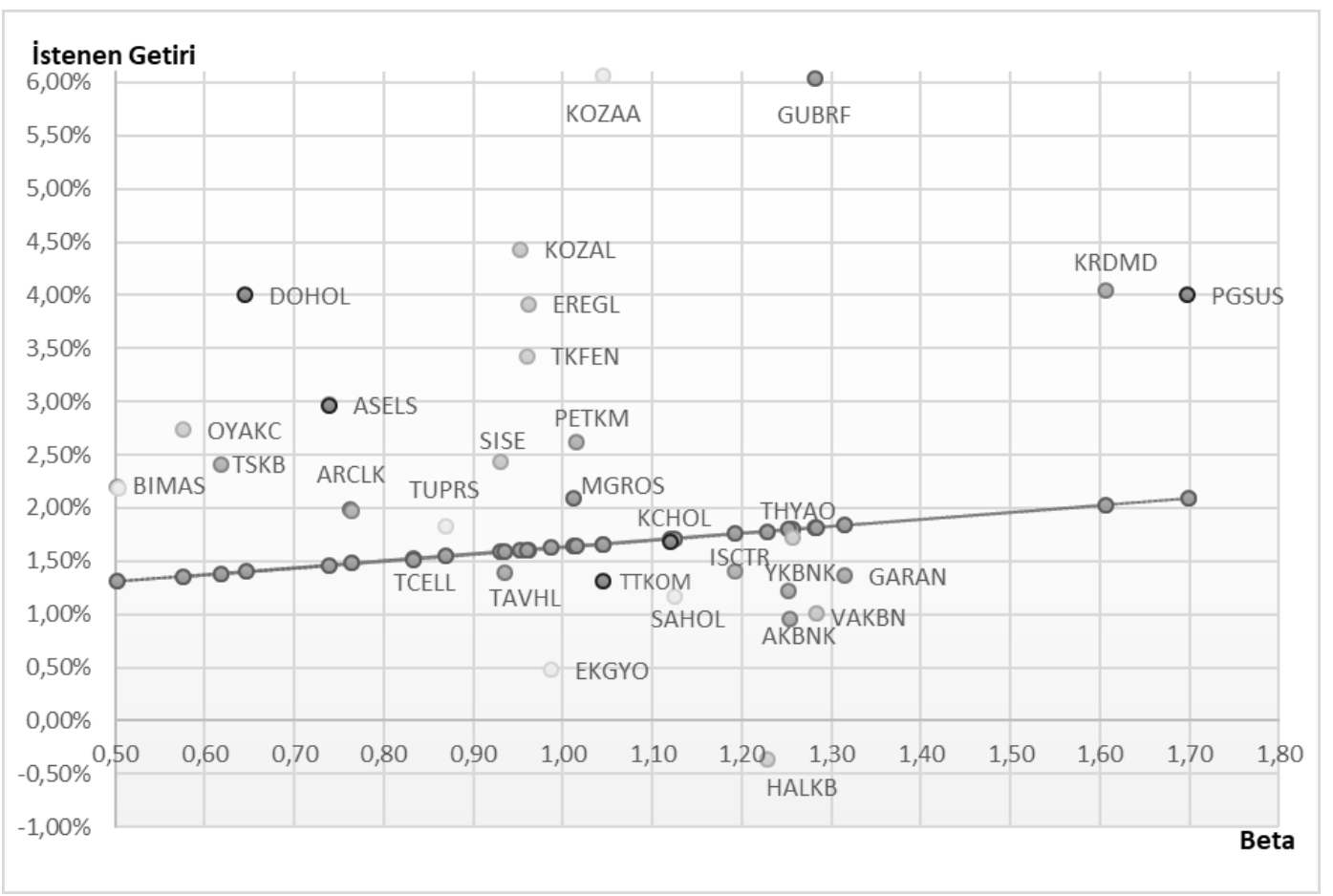

Şekil 2: Finansal Varlık Pazar Doğrusu (Risk Ölçütü: Beta)

Tablo (2)'ye göre 13 adet pay negatif alfalıdır. Şekil (2)'ye göre de ilgili paylar FVPD’nin altındadır. $\mathrm{Bu}$ paylar aktif strateji takip eden yatırımcıların portföylerinde azaltılmalı veya yer almamalıdır. Negatif alfaların ortalaması - \%0,58'dir. TCELL, KCHOL ve THYAO kodlu paylar nerdeyse FVPD'de (içinde) olmasına rağmen bir miktar negatif alfaya sahiptir (sırasıyla - \%0,01; - \%0,03; - \%0,07). Bu paylar için CAPM'in önerdiği getiri ve gerçekleşen getiriler neredeyse eşittir. Bu da ilgili paylardaki fiyatlamanın doğruluğunu göstermektedir. Önemli bulgulardan bir diğeri de bankacılık sektöründeki tüm payların - TSKB hariç - negatif alfaya sahip olmasıdır. Diğer bir ifadeyle bu payların tamamı pahalıdır ve portföylerdeki ağırlıkları azaltılmalı veya portföyden çıkarılmalıdır.

D-CAPM'in önerdiği getiriler ile payların gerçekleşen getirileri karşılaştırıldığında yine 17 adet pay pozitif alfalıdır (Bkz.: Tablo 3 ve Şekil 3). Doğrunun üzerinde yer alan pozitif alfalı payların önerdiği aylık ilave getiri, ortalama \%1,62'dir. Geri kalan 13 pay negatif alfalı olsa da TCELL ve KCHOL neredeyse FVPD'dedir. Yine önemli bulgulardan bir diğeri de bankacılık sektöründeki tüm payların - TSKB hariç - negatif alfaya sahip olmasıdır. 


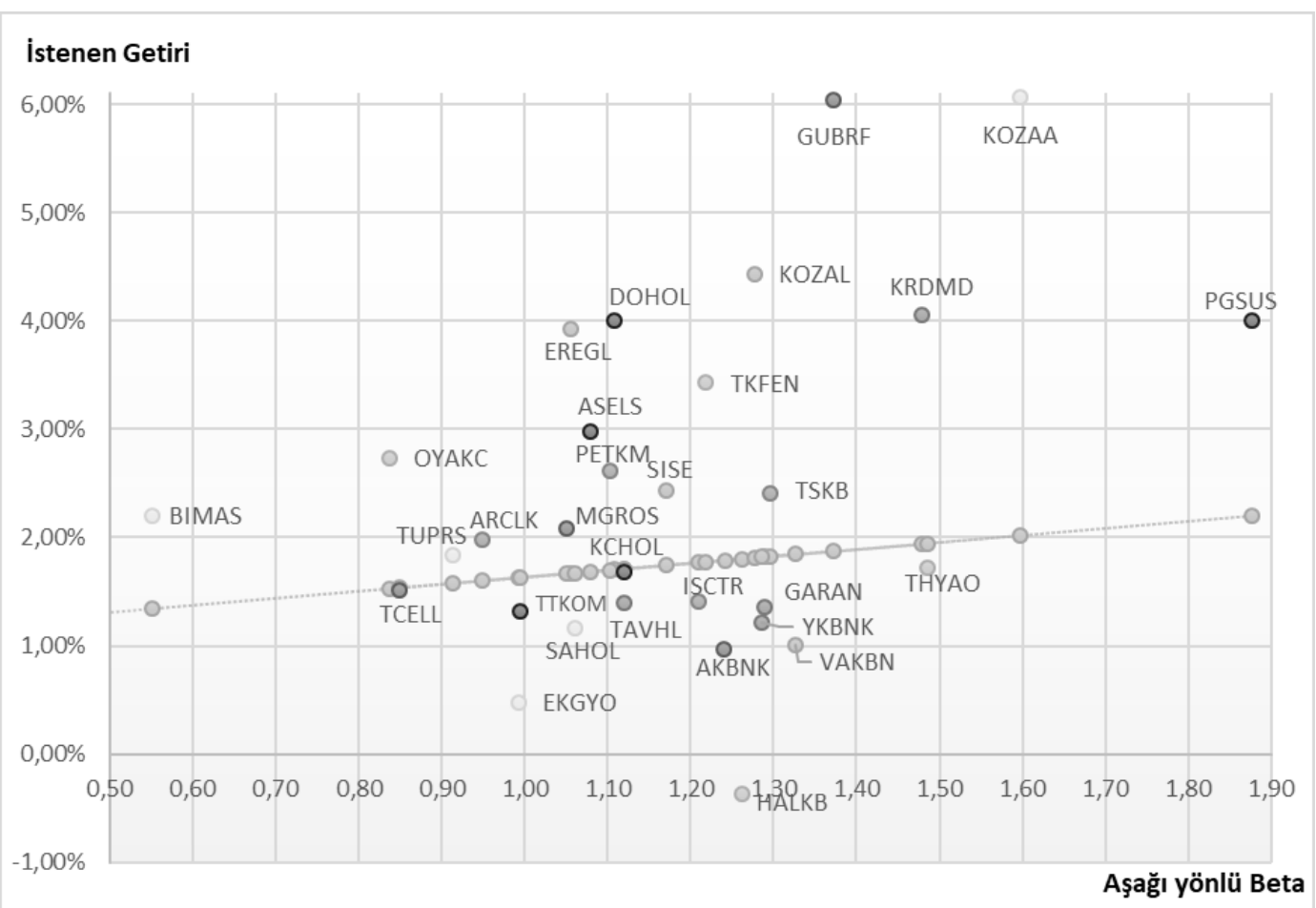

Şekil 3: Finansal Varlık Pazar Doğrusu (Risk Ölçütü: Aşağı yönlü Beta)

Hem CAPM hem de D-CAPM ile yapılan analizde alfa değerleri birbirlerinden farklı olsa da pozitif ve negatif alfalı paylar aynıdır. Bu da portföy seçiminde CAPM ve D-CAPM'in benzer sonuçlara işaret ettiğini göstermektedir. Benzer sonuçlar - doğal olarak - modellerin önerdiği getirilerin çok yakın olması ile ilişkili olabilir. Tüm paylar için CAPM’in önerdiği getirilerin ortalaması \%1,65 iken D-CAPM'in önerdiği getirilerin ortalaması \%1,74’tür. Aradaki oransal fark sadece \%5,5’tir. Her iki modelde de kullanılan risksiz faiz oranı $(\% 0,98)$ ve piyasa risk primi $(\% 0,65)$ aynıdır. Risksiz faiz oranındaki değişim CAPM ve D-CAPM tarafından önerilen getirileri değiştirebilir. Bununla birlikte doğrunun üzerindeki ve altındaki payları da değiștirebilir. Fakat risksiz faiz oranındaki değişim, doğrunun altındaki ve üzerindeki payları modelden modele farklılaştıramaz. Başka bir ifade ile FVPD’nin y eksenin kestiği noktanın aşağı veya yukarı kayması, iki model için de eşdeğer bir etki yaratacaktır. Piyasa risk primindeki değişim ise doğruların eğimini değiştirecektir. Piyasa risk primindeki değişim, beta ile veya aşağı yönlü beta ile çarpıldığında modellerin sonuçlarında dolaylı bir değişikliğe neden olabilecektir.

CAPM ve D-CAPM’e göre çizilmiş finansal varlık pazar doğrularının yer aldığı Şekil (2) ve Şekil (3)'de payların y eksenindeki izdüşümleri aynıdır ve gerçekleşen getirileri (Ri) temsil etmektedir. Şekil (2) ve Şekil (3)'deki grafikleri farklılaştıran tek parametre ise payların x eksenindeki izdüşümleri, 
diğer bir ifade ile betaları ve aşağı yönlü betalarıdır. Payların betalarının ortalaması 1,03 iken tüm betalar 0,50 ile 1,70 aralığındadır. Payların aşağı yönlü betalarının ortalaması ise 1,17 iken tüm aşağ 1 yönlü betalar 0,55 ile 1,88 aralığındadır. Aşağı yönlü betaların ortalaması ile betaların ortalaması arasındaki fark oransal olarak sadece \%13,5’tir. Beta ve aşağı yönlü beta grupları arasındaki farklılığın istatistiksel olarak anlamlı olup olmadığına karar verebilmek için t testi uygulanmıştır.

Tablo 4: Beta ve Aşağı Yönlü Beta t-Testi Sonuçları

\begin{tabular}{|c|c|c|c|c|c|c|c|}
\hline \multirow[b]{2}{*}{ Değişken } & \multicolumn{3}{|c|}{ Gözlem } & \multicolumn{4}{|l|}{ Standart } \\
\hline & Sayıs1 & & Ortalama & Sapma & Standart Hata & & \\
\hline Beta & 30 & & 1.03 & 0.006 & 0.0011 & & \\
\hline \multirow[t]{2}{*}{ Aşağg Yönlü Beta } & 30 & & 1.17 & 0.004 & 0.0007 & & \\
\hline & & df & $\mathrm{t}$ & $\begin{array}{l}\mathrm{P}(\mathrm{T}<=\mathrm{t}) \text { tek- } \\
\text { kuyruk }\end{array}$ & $\begin{array}{l}\text { t Kritik tek- } \\
\text { kuyruk }\end{array}$ & $\begin{array}{l}\mathrm{P}(\mathrm{T}<=\mathrm{t}) \text { çift- } \\
\text { kuyruk }\end{array}$ & $\begin{array}{l}\text { t Kritik iki- } \\
\text { kuyruk }\end{array}$ \\
\hline \multicolumn{2}{|c|}{ t-Test: Eşit Varyanslar } & 58 & -2.019 & $2.4 \%$ & 1.672 & $4.8 \%$ & 2.002 \\
\hline \multicolumn{2}{|c|}{ t-Test: Farklı Varyanslar } & 57 & -2.019 & $2.4 \%$ & 1.672 & $4.8 \%$ & 2.002 \\
\hline
\end{tabular}

Varyansların eşit dağıldığı ve farklı dağıldığı varsayımı altında tek ve çift kuyruklu t istatistik değerlerinin tamamı \%95 güven aralığında anlamlı çıkmıştır. Bu bulgu, iki farklı beta grubunun ortalamaları arasındaki farkın istatistiki olarak önemli olduğunu ortaya koymaktadır.

Betalar ile aşağı yönlü betalar arasındaki fark istatistiki olarak anlamlı olduğuna göre CAPM ve D-CAPM'in benzer sonuçlara işaret etmesinin başka bir nedeni de gerçekleşen getirilerin, FVPD'den oldukça uzak olması olabilir. Buradaki sav, bir örnek yardımı ile açıklanabilir. Beta ve aşağı yönlü beta arasındaki farkın oransal olarak en büyük olduğu pay TSKB’dir ( \%110). Her iki modelin bu pay için önerdiği getiriler aşağıdadır:

CAPM’in önerdiği istenen getiri:

$$
k_{T S K B}=0,98+0,62 \times(0,65)
$$

D-CAPM'in önerdiği istenen getiri:

$$
k_{T S K B}=0,98+1,30 \times(0,65)
$$

Yukarıdaki hesaplamalara göre TSKB için CAPM'in önerdiği getiri aylık \%1,38 iken D-CAPM'in önerdiği getiri aylık \%1,82'dir. Oysa aynı payın gerçekleşen getirisi \%2,41'dir. Bu durumda TSKB her iki modele göre de FVPD’nin üzerindedir. Beta ve aşağı yönlü betalar arasındaki farkın en büyük olduğu payda bile iki yöntem de benzer sonuçlara işaret etmektedir. Nihai olarak bu bulgular portföy seçiminde CAPM ve D-CAPM kullanımının neden benzer sonuçlar sunduğunun kanıtları olabilir.

\section{Sonuçlar}

Çalışma ortalama-semivaryans yaklaşımından türetilen, alternatif bir fiyatlama modeli olan D-CAPM'in, portföy seçiminde ortalama-varyans yaklaşımından türetilen CAPM'den farklı sonuçlar 
ortaya koyup koymadığı araştırmayı amaçlamaktaydı. Bu amaçla tek endeksli modelin sabitli ve sabitsiz versiyonları, BIST30 endeksine dahil olan payların betalarını ve aşağı yönlü betalarını hesaplamak için kullanılmıştır. Betalar ve aşağı yönlü betalar kullanılarak her bir pay için CAPM ve D-CAPM'in önerdiği istenen getiriler hesaplanmış ve bu getiriler, payların gerçekleșen getirileri ile karşılaştırılmıştır.

BIST30 endeksinde yer alan 24 adet payın betası, aşağı yönlü betasından ortalama \%22,6 büyük iken kalan 6 adet payın betası, aşağı yönlü betasından sadece \%3,6 büyüktür. Bu bulgu literatür ile tutarlı olarak D-CAPM'in daha yüksek istenen getiriler üretmesine neden olmaktadır. Dolayısıyla D-CAPM'in, özellikle gelişmekte olan ülkelerde - ülke riskini de içerebilecek - daha adil bir fiyatlamaya neden olacağı düşünülebilir.

Çalışmanın sonuçlarından birisi de ortalama semivaryans yaklaşımı ile yapılan çeşitlendirmenin riski düşürmedeki başarısının, ortalama-varyans yaklaşımından daha iyi olmadığıdır. Bu sonucun önemli sebeplerinden birisi de pay çiftleri arasındaki aşağı yönlü korelasyon katsayılarının, korelasyon katsayılarından ortalama olarak daha yüksek oluşudur. Her bir payın borsa endeksiyle olan aşağı yönlü korelasyon katsayısının, korelasyon katsayısından yüksek oluşu da diğer bir sebeptir. Bu sonuç, piyasalarda aşağı yönlü volatilitenin arttığı dönemlerde varlık getirilerinin daha yüksek korelasyonlara sahip olduğunu söyleyen literatür ile tutarlıdır (Odier \& Solnik 1993; Beach, 2006; Damodaran, 2013; Bekaert \& Harvey, 2013)

Her iki yaklaşıma göre de 19 adet payın Sharp rasyosu piyasa endeksinin Sharp rasyosundan büyüktür. Bu sonuç, BIST100 endeksinin hem ortalama-varyans hem de ortalama-semivaryans yaklaşımına göre etkin olmadığını gösterebilir.

Betalar ve aşağı yönlü betalar arasındaki fark, istatistiksel olarak anlamlı olmasına rağmen hem CAPM hem de D-CAPM kullanılarak portföye alınması veya portföyden çıkarılması gereken payların benzer olması çalışmanın en önemli sonuçlarından birisidir.

Literatür - özellikle - gelişmekte olan ülkelerde, aşağ1 yönlü risk ölçütlerinin istatistiksel olarak daha anlamlı olduğunu ileri sürse de ilgili çalışma, aktif strateji izleyen yatırımcıların hem aşağı yönlü beta hem de beta kullanarak oluşturduğu FVPD’nin, portföy seçiminde benzer sonuçlar ortaya koyduğunu göstermektedir.

Gelişmekte olan piyasalar için piyasa risk primi hesaplanmasındaki güçlükler, betanın durağan olmaması ve yatırım ufkunun kısa olmasından dolayı risk değişkenlerinin hesaplanmasında uzun bir veri seti kullanılamaması, çalışmanın kısıtları arasında yer almaktadır.

\section{Yazar Katkısı}

Çalışmanın bütün aşamaları Mehmet Emin YILDIZ tarafından yürütülmüştür.

\section{Çıkar Çatışması}

Çalışmada yazarlar arasında çıkar çatışması yoktur. 


\section{Finansal Destek}

Bu çalışma için herhangi bir kurumdan destek alınmamıştır.

\section{Kaynakça}

Ali, H. (2019). Does downside risk matter more in asset pricing? Evidence from China. Emerging Markets Review, 39, 154-174.

Alles, L., \& Murray, L. (2008). Downside risk in emerging markets. European financial management association annual meetings, Athens, June, 25-28.

Arrow, K.J. (1971). Essays in the Theory of Risk-Bearing. Chicago: Markham Publishing Company.

Ang, A., Chen, J., \& Xing, Y. (2006). Downside Risk. The Review of Financial Studies, 19(4), 1191-1239.

Atilgan, Y., \& Demirtas, O. (2013). Downside Risk in Emerging Markets. Emerging Markets Finance and Trade, 49, 64-83.

Beach, S. L. (2006). Why emerging market equities belong in a diversified investment portfolio. Journal of Investing, 15(4), 12-18.

Beach, S. L. (2011). Semivariance decomposition of country-level returns. International Review of Economics and Finance, 20(4), 607-623.

Bekaert, G., \& Harvey, C.R. (2017). Emerging Equity Markets in a Globalizing World. http://dx.doi.org/10.2139/ ssrn.2344817.

Bodie, Z., Kane, A., \& Marcus, A.J. (2009). Investments, New York, NY: McGraw-Hill.

Bodnar, G. M., Bernard D., \& Richard D. M. (2003). Cross-border valuation: The international cost of equity capital. NBER Working Paper 10115. Erişim Adresi: https://papers.ssrn.com/sol3/papers.cfm?abstract_ $\mathrm{id}=471465$.

Brealey, R.A., Myers, S.C., \& Allen, F. (2008). Principles of Corporate Finance. International Edition. New York, NY: McGraw Hill.

Donadelli, M., \& Prosperi, L. (2011). The Equity Risk Premium: Empirical Evidence from Emerging Markets. CASMEF Working Paper. http://dx.doi.org/10.2139/ssrn.1893378.

Erb, C., B., Harvey, C.R., \& Viskanta, T., (1995). Country risk and global equity selection. The Journal of Portfolio Management, 21(2), 74-83.

Estrada, J. (2000). The Cost of Equity in Emerging Markets: A Downside Risk Approach. Emerging Markets Quarterly, 4, 19-30.

Estrada, J. (2001). The Cost of Equity in Emerging Markets: A Downside Risk Approach (II), Emerging Markets Quarterly, Spring, 63-72. http://dx.doi.org/10.2139/ssrn.249579.

Estrada, J. (2002). Systematic Risk in Emerging Markets: The D-CAPM. Emerging Markets Review, 3 (3), 365 379.

Estrada, J. (2003). Mean-Semivariance behavior (II): the D-CAPM. Working Paper, IESE Business School, 2-17.

Estrada, J., \& Serra, P. A. (2005). Risk and Return in Emerging Markets: Family Matters. Journal of Multinational Financial Management, 15, 257-272.

Faff, R.W., \& Lau, S., (1997). A generalised methods of moments test of mean variance efficiency in the Australian stock market. Pacific Accounting Review 9, 2-16.

Feldstein, M.S. (1969). Mean-variance analysis in the theory of liquidity preference and portfolio selection. Review of Economic Studies, 36(1), 5-12. 
Fuenzalida, D., \& Mongrut, S.A. (2010). Estimation of Discount Rates in Latin America: Empirical Evidence and Challenges. Journal of Economics, Finance and Administrative Science, 15(28), 7-43.

Foong, S.-S., \& Goh, K.-L. (2010). Measuring the cost of equity of emerging market firms: the case of Malaysia. Asian Academy of Management Journal of Accounting and Finance, 6(1), 25-46.

Galagedera, D.U.A. (2007). An alternative perspective on the relationship between downside beta and CAPM beta. Emerging Markets Review, 8(1), 4-19.

Galagedera, D.U.A, \& Brooks, R. D. (2007). Is co-skewness a better measure of risk in the downside than downside beta? Evidence in Emerging Market Data. Journal of Multinational Financial Management, 17, 214-230.

Godfrey, S., \& Espinosa, R. (1996). A Practical Approach to Calculating Costs of Equity for Investments in Emerging Markets. Journal of Applied Corporate Finance, 9(3), 80-90.

Grootveld, H., \& Hallerbach, W. (1999). Variance vs downside risk: Is there really that much difference? European Journal of Operational Research, 114(2), 304-319.

Gul, F. (1991). A Theory of Disappointment Aversion. Econometrica, 59(3), 667- 686.

Harvey, C. R. (2000). Drivers of Expected Returns in International Markets. Emerging Markets Quarterly, Fall, 1-17. http://dx.doi.org/10.2139/ssrn.795385.

Harvey, C. R. (2001). The International Cost of Capital and Risk Calculator (ICCRC). Duke University Working Paper, 1-20.

Hicks, J.R. (1935). Annual survey of economic theory: the theory of monopoly. Econometrica: Journal of the Econometric Society, 3(1), 1-20.

Hwang S., \& Pedersen, C.S. (2002). Best practice risk measurement in emerging markets: empirical test of asymmetric alternatives to CAPM, Working Paper, Cass Business School, UK.

Kahneman, D., \& Tversky, A., (1979). Prospect Theory: An Analysis of Decision Under Risk. Econometrica, 47(2), 263-291.

Kandel, S. (1984). On the Exclusion of Assets from Tests of the Mean-Variance Efficiency of the Market Portfolio. The Journal of Finance, 39(1), 63-7.

Kaplan, P. D., \& Laurence B. S. (1994). Portfolio Theory Is Alive And Well. Journal of Investing, 3(3), 18-23.

Kim, E. H, \& Vijay S. (1997). Are Open Markets Good for Foreign Investors and Emerging Nations? Journal of Applied Corporate Finance, 10(3), 18-33.

Lessard, D. R. (1996). Incorporating Country Risk in the Valuation of Offshore Projects. Journal of Applied Corporate Finance, 9(3), 52-63.

MacKinlay, A. C., \& Matthew P. R. (1991). Using Generalized Method of Moments to Test Mean-Variance Efficiency. Journal of Finance, 46(2), 511-527.

Mariscal, J. O., \& LEE, R. M. (1993). The Valuation of Mexican Stocks: an Extension of Capital Asset Pricing Model to Emerging Markets. Goldman Sachs Investment Research, 2-16.

Markowitz, H. (1952). Portfolio Selection. Journal of Finance, 12, 77-91.

Markowitz, H. M. (1959). Portfolio Selection (First Edition). New York: John Wiley and Sons.

Markowitz, H. M. (1991). Portfolio Selection (Second Edition). Cambridge, MA: Basil Blackwell, Inc.

Marschak, J. (1938). Money and the Theory of Assets. Econometrica, 6, 311-325.

Nawrocki, D. N. (1999). A Brief History of Downside Risk Measures. The Journal of Investing, 8 (2), 9-25.

Odier, P., \& B. Solnik. (1993). Lessons for International Asset Allocation. Financial Analysts Journal, 49(2), 63-

77. 
Okyere-Boakye, K., \& O’Malley, B. (2016). Downside CAPM: the case of South Africa. Journal of Economic and Financial Studies, 9(2), 578-608.

Pereiro, L. E. (2001). The valuation of closely-held companies in Latin America, Emerging Market Review, 2001, 330-370.

Pratt, J. (1964). Risk Aversion in the Small and in the Large. Econometrica, 32(1/2), 122-136.

Riddles, N. (2001). A Portfolio Manager's View on Downside Risk. In F. A. Sortino \& S. Satchell (Eds.). Managing Downside Risk in Financial Markets: Theory, Practice And Implementation, 93-100. Oxford, UK: Butterworth Heinemann.

Rom, B. M., \& Ferguson, K.W. (1994). Post-Modern Portfolio Theory Comes Of Age. Journal of Investing, 3(3), 11-17.

Roy, A. D. (1952). Safety First And The Holding Of Assets. Econometrica, 20(3), 431-449.

Salomons, R., \& Grootveld, H. (2003). The Equity Risk Premium: Emerging vs. Developed Markets. Emerging Markets Review, 4, 121-144.

Searle, S.R. (1971). Linear Models. New York: John Wiley \& Sons.

Sharpe, N.F. (1964). Capital Asset Prices: A Theory of Market Equilibrium Under Conditions of Risk. Journal of Finance, 19(3), 425-442.

Susmel, R., (2001). Extreme Observations And Diversification in Latin American Emerging Equity Markets. Journal of International Money and Finance, 20, 971-986.

Teplova, T. ve E. Shutova. (2011). A Higher Moment Downside Framework for Conditional and Unconditional CAPM in The Russian Stock Market. Eurasian Economic Review, 1(2), 157-178.

Tsai, H. J., Chen, M. C. ve Yang, C. Y. (2014). A Time-Varying Perspective on The Capm and Downside Betas. International Review of Economics and Finance, 29, 440-454.

Williams, J. B. (1938). The Theory of Investment Value (North Holland Publishing, Amsterdam); reprinted 1997 (Fraser Publishing, Burlington, VT).

Yildiz, M.E., \& Erzurumlu, Y.O. (2018). Testing Postmodern Portfolio Theory Based On Global And Local Single Factor Market Model: Borsa Istanbul case. Borsa Istanbul Review, 18(4), 259-268.

Yildiz, M.E., Erzurumlu, Y.O., \& Kurtulus, B. (2020). Comparative Analyses Of Mean-Variance And Mean-Semi Variance Approaches On Global And Local Single Factor Market Model For Developed And Emerging Markets. International Journal of Emerging Markets. doi: 10.1108/IJOEM-01-2020-01.

\section{Özgeçmiş}

Mehmet Emin YILDIZ (Dr. Öğr. Üyesi), Doğuş Üniversitesi, İktisadi ve İdari Bilimler Fakültesi, İşletme bölümünde Dr. Öğretim Üyesi olarak görev yapmaktadır. Anadolu Üniversitesi İktisadi ve İdari Bilimler Fakültesi İşletme Bölümünde lisans öğrenimini, Finansman Bölümünde ise yüksek lisans öğrenimini tamamlamıştır. 2015 yılında İstanbul Üniversitesi Finans Bilim dalından Doktora derecesini almıştır. Portföy Yönetimi, Sermaye Piyasaları ve Değerleme üzerine çalışmalarını sürdürmektedir. 


\section{EK 1: Korelasyon Katsayıları}

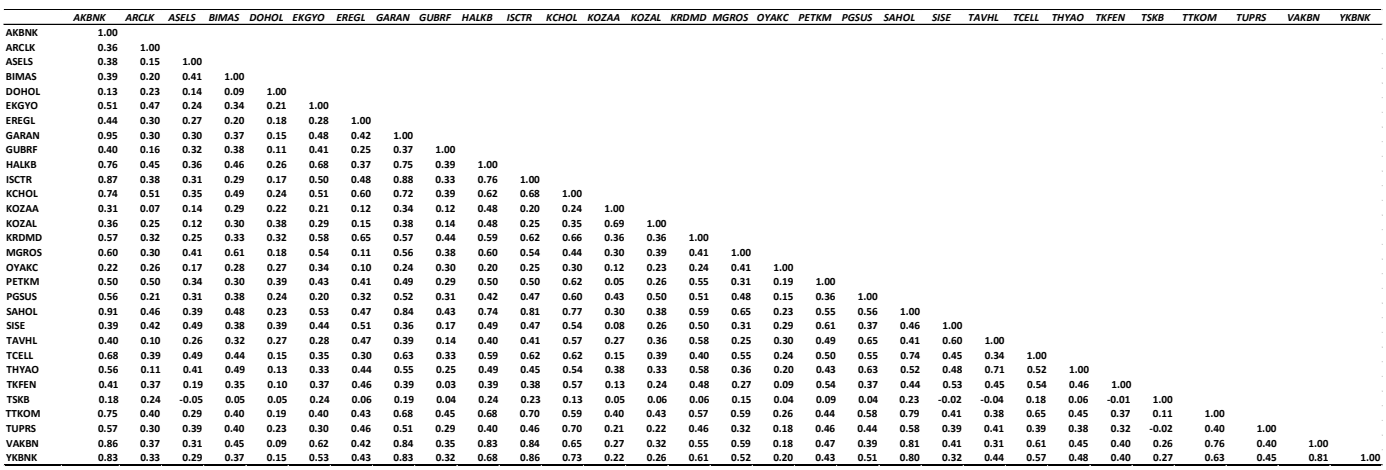

EK 2: Aşağı Yönlü Korelasyon Katsayıları

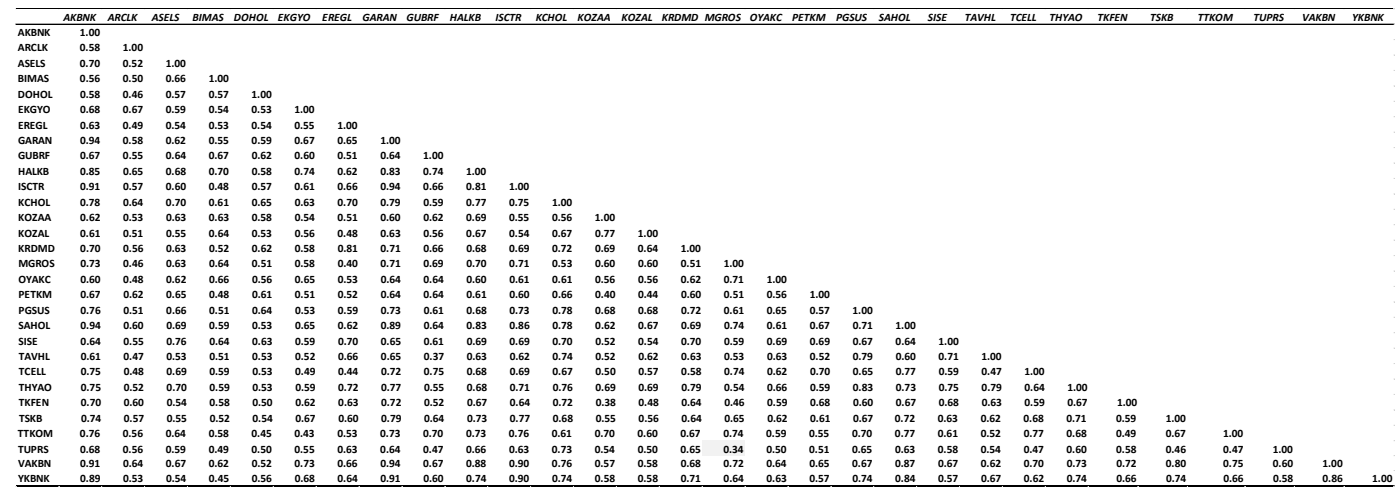

